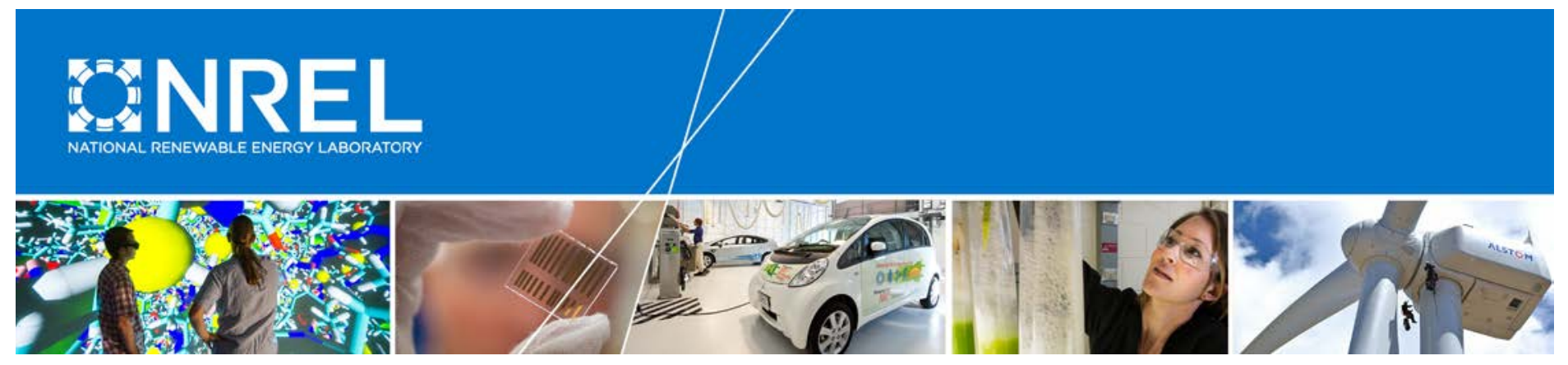

\title{
Challenges and Opportunities for Transactive Control of Electric Vehicle Supply Equipment: A Reference Guide
}

Xin Jin and Andrew Meintz National Renewable Energy Laboratory

NREL is a national laboratory of the U.S. Department of Energy Office of Energy Efficiency \& Renewable Energy Operated by the Alliance for Sustainable Energy, LLC

This report is available at no cost from the National Renewable Energy Laboratory (NREL) at www.nrel.gov/publications.

Technical Report

NREL/TP-5500-64007

July 2015

Contract No. DE-AC36-08GO28308 


\section{Challenges and Opportunities for Transactive Control of Electric Vehicle Supply Equipment: A Reference Guide}

Xin Jin and Andrew Meintz

National Renewable Energy Laboratory

Prepared under Task No. BE4S.4440
NREL is a national laboratory of the U.S. Department of Energy Office of Energy Efficiency \& Renewable Energy Operated by the Alliance for Sustainable Energy, LLC

This report is available at no cost from the National Renewable Energy Laboratory (NREL) at www.nrel.gov/publications.
National Renewable Energy Laboratory 15013 Denver West Parkway Golden, CO 80401

303-275-3000 • www.nrel.gov
Technical Report NREL/TP-5500-64007 July 2015

Contract No. DE-AC36-08GO28308 


\title{
NOTICE
}

This report was prepared as an account of work sponsored by an agency of the United States government. Neither the United States government nor any agency thereof, nor any of their employees, makes any warranty, express or implied, or assumes any legal liability or responsibility for the accuracy, completeness, or usefulness of any information, apparatus, product, or process disclosed, or represents that its use would not infringe privately owned rights. Reference herein to any specific commercial product, process, or service by trade name, trademark, manufacturer, or otherwise does not necessarily constitute or imply its endorsement, recommendation, or favoring by the United States government or any agency thereof. The views and opinions of authors expressed herein do not necessarily state or reflect those of the United States government or any agency thereof.

This report is available at no cost from the National Renewable Energy Laboratory (NREL) at www.nrel.gov/publications.

Available electronically at SciTech Connect http:/www.osti.gov/scitech

Available for a processing fee to U.S. Department of Energy and its contractors, in paper, from:

\author{
U.S. Department of Energy \\ Office of Scientific and Technical Information \\ P.O. Box 62 \\ Oak Ridge, TN 37831-0062 \\ OSTI http://www.osti.gov \\ Phone: 865.576.8401 \\ Fax: 865.576.5728 \\ Email: reports@osti.gov
}

Available for sale to the public, in paper, from:

\author{
U.S. Department of Commerce \\ National Technical Information Service \\ 5301 Shawnee Road \\ Alexandria, VA 22312 \\ NTIS http://www.ntis.gov \\ Phone: 800.553 .6847 or 703.605 .6000 \\ Fax: 703.605.6900 \\ Email: orders@ntis.gov
}




\section{Acknowledgments}

The authors would like to thank Joe Hagerman and George Hernandez of the U.S. Department of Energy for their support. The authors would also like to extend their gratitude to the following people for their contributions to the report: Chuck Booten, Dane Christensen, Lieko Earle, and Jon Winkler. 


\section{List of Acronyms}

$\mathrm{AC}$

ANL

BEV

DC

DOE

DR

EV

EVSE

ESIF

HIL

HVAC

$\mathrm{kW}$

kWh

NREL

PEV

PG\&E

PHEV

PNNL

PV

R\&D

SAE

TOU

$\mathrm{V} 2 \mathrm{~B}$

$\mathrm{V} 1 \mathrm{G}$

V2G

VGI alternating current

Argonne National Laboratory

battery electric vehicle

direct current

U.S. Department of Energy

demand response

electric vehicle

electric vehicle supply equipment

Energy Systems Integration Facility

hardware-in-the-loop

heating, ventilating, and air conditioning

kilowatt

kilowatt-hour

National Renewable Energy Laboratory

plug-in electric vehicle

Pacific Gas \& Electric Company

plug-in hybrid electric vehicle

Pacific Northwest National Laboratory

photovoltaic

research and development

Society of Automotive Engineers

time-of-use

vehicle to building

vehicle to grid, unidirectional

vehicle to grid, bidirectional

vehicle grid integration 


\section{Executive Summary}

Grid integration of electric vehicle supply equipment (EVSE) offers the potential to provide various types of services to utilities, society, and electric vehicle owners. Transactive control can greatly facilitate EVSE integration because it enables market-based coordination to optimize energy efficiency, reduce energy cost, manage energy use, and control emissions. Yet many EVSE units lack the communication and control capabilities that are needed for effective grid integration. Building owners and utilities are uncertain about how to take advantage of these new assets.

This report seeks to characterize the opportunities and challenges that arise in developing a transactive control strategy for grid-EVSE integration in various use-case scenarios in a way that provides end-user, energy market, grid, and societal benefits. A detailed review provides information about EVSE integration market trends and stakeholder activities. This is followed by an exploration of value proposition for transactive control of EVSE at both the home scale and the building/campus scale. This report will serve as a reference guide for stakeholders in the grid-EVSE integration area, illustrate potential implementations, and identify a high-value research project for overcoming the barriers and unlocking the benefits of transactive controls of EVSE. While it is not intended to specify the technical details of the transactive control solution, the report contains a list of use cases describing potential applications of transactive control of EVSE, barriers to implementing these applications, and research and development (R\&D) opportunities to overcome the barriers. The use cases of transactive control of EVSE are listed in Table ES1.

Barriers to transactive control of EVSE arise in many areas of research, including distribution infrastructure, standardization, vehicle-building/grid integration, and large-scale demonstration. See Figure ES1 to view the barriers and R\&D opportunities of transactive control of EVSE. A detailed explanation of these barriers and opportunities is provided in Table ES2. VOLTTRON, ${ }^{1}$ a freely available agent-based platform that was developed by Pacific Northwest National Laboratory, is best suited for transactive control in the environment described in Figure ES1. VOLTTRON enables the interactions between distributed energy resources, buildings, EVSE units, plug-in electric vehicles (PEVs), service providers, and aggregators to achieve energyefficient grid integration.

To begin addressing the identified gaps and barriers, the National Renewable Energy Laboratory is proposing a project to unlock the many benefits of transactive controls and facilitate wide adoption of VOLTTRON by industry stakeholders. This project will leverage the expertise of multiple national laboratories to overcome these barriers and demonstrate transactive control of EVSE. The project will utilize a transactive network infrastructure such as the scalable VOLTTRON infrastructure in the Energy Systems Integration Facility at the National Renewable Energy Laboratory.

\footnotetext{
${ }^{1}$ VOLTTRON can be downloaded from http://gridoptics.pnnl.gov/VOLTTRON/.
} 
Table ES1. A List of Use Cases Describing Potential Applications of Transactive Control of EVSE

\begin{tabular}{|c|c|c|}
\hline $\begin{array}{l}\text { Service } \\
\text { Category }\end{array}$ & Use Cases & Description \\
\hline \multirow{4}{*}{$\begin{array}{l}\text { End-User } \\
\text { Services }\end{array}$} & Critical load support & $\begin{array}{l}\text { Provide outage support to the critical loads of the home with the } \\
\text { energy in the PEV. Plug-in hybrid electric vehicles are more } \\
\text { suitable for critical load support than battery electric vehicles } \\
\text { because a grid outage is unexpected. }\end{array}$ \\
\hline & $\begin{array}{l}\text { Charging capacity } \\
\text { deferral }\end{array}$ & $\begin{array}{l}\text { Reduce the EVSE installation cost by planning and managing } \\
\text { charge times. Require information from the driver. The cost } \\
\text { reduction is significant in large deployment scenarios. }\end{array}$ \\
\hline & $\begin{array}{l}\text { Trading positions in a } \\
\text { charging queue at a } \\
\text { multiplex EVSE }\end{array}$ & $\begin{array}{l}\text { The user monetizes the convenience of the quick departure time } \\
\text { and pays more than the energy costs. }\end{array}$ \\
\hline & $\begin{array}{l}\text { Monetizing delayed } \\
\text { EVSE charging to } \\
\text { prioritize fast charging }\end{array}$ & $\begin{array}{l}\text { Incentivize the delayed charging of Level } 2 \text { EVSE to reduce the } \\
\text { peak demand charge associated with the direct current fast } \\
\text { charger. Also reduce the stress on distribution transformers. }\end{array}$ \\
\hline \multirow{4}{*}{$\begin{array}{l}\text { Energy } \\
\text { Market } \\
\text { Services }\end{array}$} & Dynamic pricing & $\begin{array}{l}\text { Benefit from lower charging rates by optimizing PEV charging for } \\
\text { dynamic rate, which may be either real-time or time-of-use. }\end{array}$ \\
\hline & $\begin{array}{l}\text { Local renewable } \\
\text { energy integration }\end{array}$ & $\begin{array}{l}\text { Benefit from local renewable energy generation and store the } \\
\text { energy locally using PEVs. This could avoid PEV recharging at } \\
\text { higher rate when local renewable energy is not available. }\end{array}$ \\
\hline & Energy arbitrage & $\begin{array}{l}\text { Reduce energy costs in a dynamic pricing environment by } \\
\text { recharging the PEV at a lower rate during nighttime and } \\
\text { discharging the PEV at higher rate. }\end{array}$ \\
\hline & $\begin{array}{l}\text { Peak demand } \\
\text { reduction }\end{array}$ & $\begin{array}{l}\text { Reduce peak demand charge by coordinating EV charging and } \\
\text { making it noncoincidental to building peak load. }\end{array}$ \\
\hline \multirow{4}{*}{$\begin{array}{l}\text { Grid } \\
\text { Services }\end{array}$} & $\begin{array}{l}\text { Distribution capacity } \\
\text { deferral }\end{array}$ & $\begin{array}{l}\text { Use a transactive control method to defer the cost of upgrading } \\
\text { transformers that may be strained by PEV charging through } \\
\text { coordinated charging behind the distribution transformer. }\end{array}$ \\
\hline & Demand response & $\begin{array}{l}\text { Demand response of EVSE may be more effective than curtailing } \\
\text { other residential loads because of its power rating. }\end{array}$ \\
\hline & Ancillary market & $\begin{array}{l}\text { EVSE owners can benefit financially by participating in ancillary } \\
\text { markets through an aggregator and providing grid services such } \\
\text { as frequency regulation and spinning reserves. }\end{array}$ \\
\hline & $\begin{array}{l}\text { Power quality } \\
\text { management }\end{array}$ & $\begin{array}{l}\text { EVSE can provide reactive power compensation for the utility to } \\
\text { increase the power transfer efficiency through transmission lines. }\end{array}$ \\
\hline
\end{tabular}




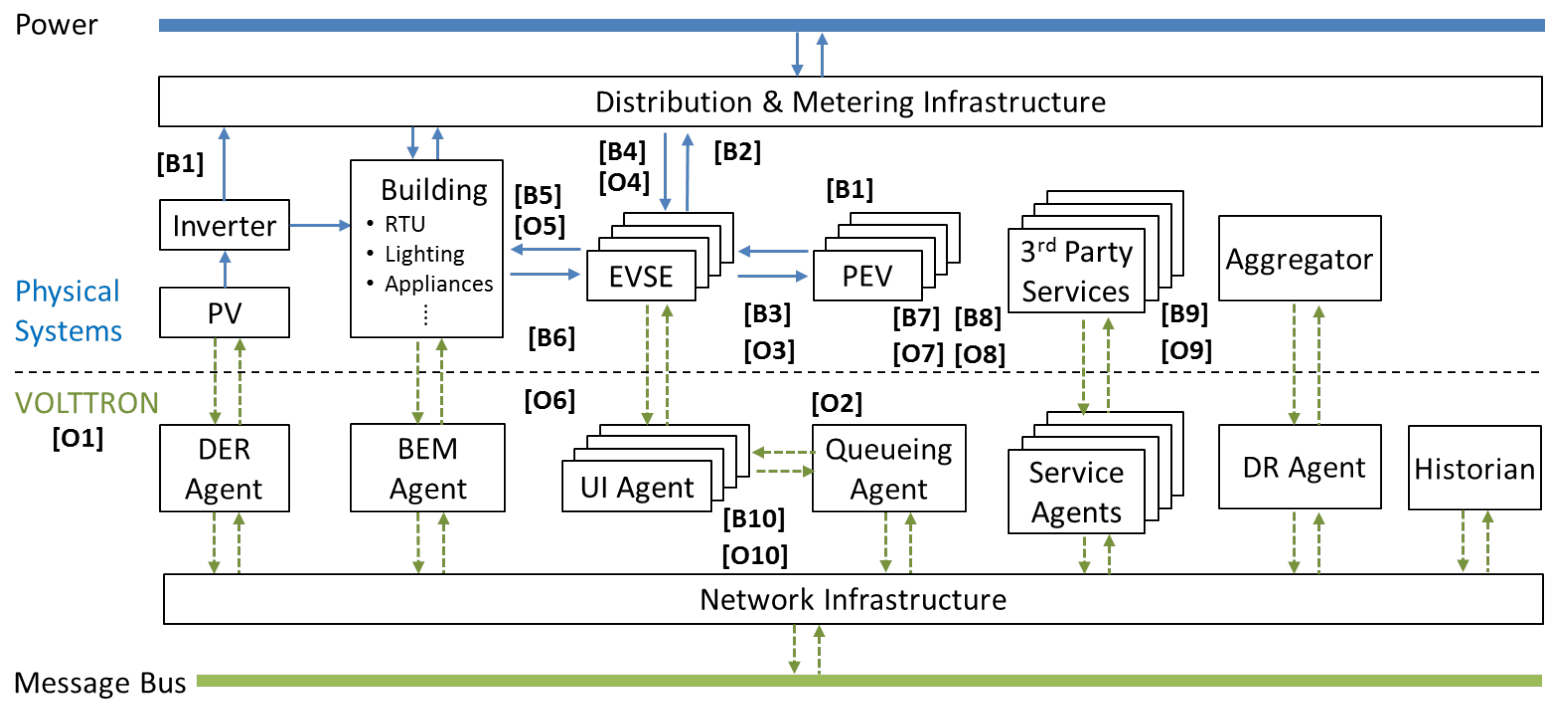

$\longrightarrow$ : Power flow in the physical systems

[B\#]: Barriers

$-------\rightarrow$ : Communications enabled by VOLTTRON

[O\#]: R\&D Opportunities

Figure ES1. A block diagram illustrating challenges and opportunities for transactive control of EVSE 
Table ES2. Barriers to Transactive Control of EVSE and Strategic R\&D Opportunities

\begin{tabular}{|c|c|c|}
\hline Category & Barriers & R\&D Opportunities \\
\hline $\begin{array}{l}\text { Distribution } \\
\text { Infrastructure }\end{array}$ & $\begin{array}{l}\text { [B1] Conventional grid management uses } \\
\text { centralized control, which may no } \\
\text { longer be adequate to manage } \\
\text { distributed generation and EVSE. } \\
\text { [B2] The maximum EVSE hosting } \\
\text { capacity in a building is limited by the } \\
\text { power distribution infrastructure to } \\
\text { avoid overload caused by } \\
\text { coincidental peak loads from EVSE } \\
\text { and existing building end uses. }\end{array}$ & $\begin{array}{l}\text { [O1] Explore distributed management } \\
\text { tools such as VOLTTRON, an agent- } \\
\text { based control platform, for } \\
\text { grid/building integration of EVSE. } \\
\text { [O2] Develop transactive control } \\
\text { algorithms to optimize the EVSE } \\
\text { charging schedule to avoid } \\
\text { coincidental peak loads and } \\
\text { maximum EVSE hosting capacity } \\
\text { with the current infrastructure. }\end{array}$ \\
\hline Standardization & $\begin{array}{l}\text { [B3] Distributed energy resources } \\
\text { automation has multiple } \\
\text { communication standards; major } \\
\text { vehicle-grid communication } \\
\text { standards do not map directly. }\end{array}$ & $\begin{array}{l}\text { [O3] Develop technologies and tools(e.g., } \\
\text { adapters and protocol translators) to } \\
\text { integrate new standardized devices } \\
\text { with legacy systems and proprietary } \\
\text { networks. }\end{array}$ \\
\hline $\begin{array}{l}\text { Vehicle- } \\
\text { Building/Grid } \\
\text { Integration }\end{array}$ & $\begin{array}{l}\text { [B4] The energy management and } \\
\text { optimization of PEV charging and } \\
\text { discharging to the grid and buildings } \\
\text { are still at an early R\&D stage. } \\
\text { [B5] EVSE capability to perform } \\
\text { grid/building services is largely limited } \\
\text { by the cost of hardware for enabling } \\
\text { bidirectional control. } \\
\text { [B6] The effectiveness of vehicle-building } \\
\text { integration may be limited because } \\
\text { PEV and building equipment } \\
\text { availability is uncertain. }\end{array}$ & $\begin{array}{l}\text { [O4] Identify key variables and objective } \\
\text { functions for optimizing energy } \\
\text { management between EVSE units } \\
\text { and the grid/building. } \\
\text { [O5] Explore the service potential of both } \\
\text { unidirectional and bidirectional } \\
\text { control with agent-based control } \\
\text { platform for EVSE. } \\
\text { [O6] Investigate the PEV availability } \\
\text { throughout the day and the feasibility } \\
\text { of using PEVs to power various } \\
\text { building equipment such as rooftop } \\
\text { units, lighting, and appliances. }\end{array}$ \\
\hline $\begin{array}{l}\text { Large-Scale } \\
\text { Demonstration }\end{array}$ & $\begin{array}{l}\text { [B7] Limited large-scale demonstration of } \\
\text { transactive network that includes } \\
\text { EVSE and distributed energy } \\
\text { resources, especially in the areas of } \\
\text { data collection, data management, } \\
\text { and autonomous control. } \\
\text { [B8] Lack of understanding in the } \\
\text { dynamics and stability of large-scale } \\
\text { transactive markets. }\end{array}$ & $\begin{array}{l}\text { [O7] Develop hardware-in-the-loop testing } \\
\text { systems to enable rapid prototyping, } \\
\text { evaluation, and optimization of } \\
\text { components and control systems. } \\
\text { [O8] Leverage scaling studies, massively } \\
\text { parallel system simulations, } \\
\text { hardware-in-the-loop systems, or all } \\
\text { three, to study the dynamics and } \\
\text { stability of large-scale transactive } \\
\text { markets. }\end{array}$ \\
\hline $\begin{array}{l}\text { User and } \\
\text { Service } \\
\text { Provider }\end{array}$ & $\begin{array}{l}\text { [B9] Third-party service provider (e.g., } \\
\text { payment verification, prognostics, } \\
\text { and health management) is not } \\
\text { available or does not have a well- } \\
\text { defined business model in the } \\
\text { transactive market. } \\
\text { [B10] Lack of user interface for PEV } \\
\text { owners to understand the value or } \\
\text { specify the preference in participating } \\
\text { in the transactive market. }\end{array}$ & $\begin{array}{l}\text { [O9] Engage with stakeholders to develop } \\
\text { VOLTTRON agents that provide } \\
\text { various types of services and explore } \\
\text { business models that benefit service } \\
\text { providers and end users in the } \\
\text { transactive market. } \\
\text { [O10] Develop user interface agents for } \\
\text { PEV owners to specify charging } \\
\text { preferences and obtain real-time } \\
\text { charging and market updates. }\end{array}$ \\
\hline
\end{tabular}




\section{Table of Contents}

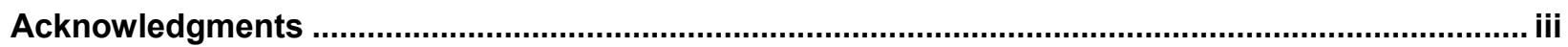

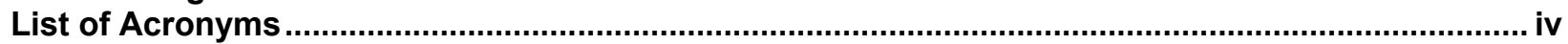

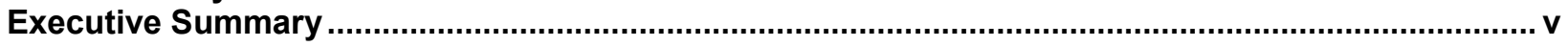

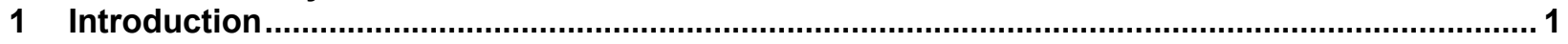

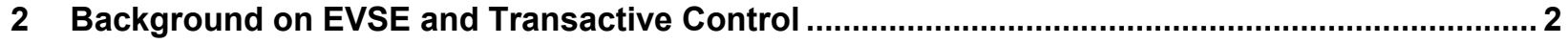

2.1 Essentials of Electric Vehicle Supply Equipment ................................................................... 2

2.2 Electric Vehicle Supply Equipment Market Trend ............................................................ 3

2.3 Impacts of Electric Vehicle Supply Equipment on the Power Grid .......................................... 4

2.4 Impact of Electric Vehicle Supply Equipment on Buildings .................................................... 5

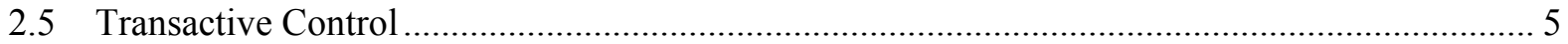

3 Stakeholder Activities in Grid-Electric Vehicle Supply Equipment Integration ........................... 8

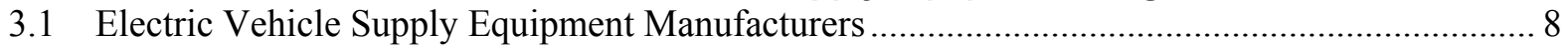

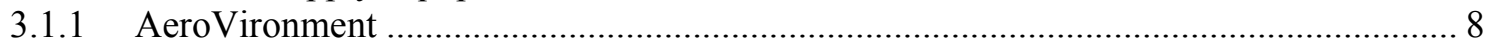

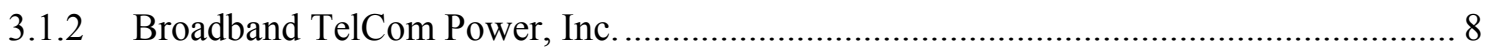

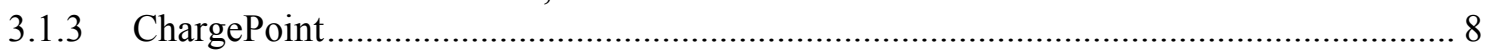

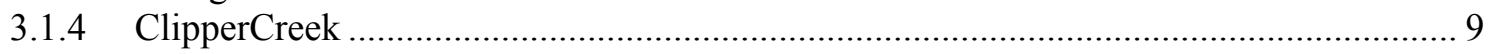

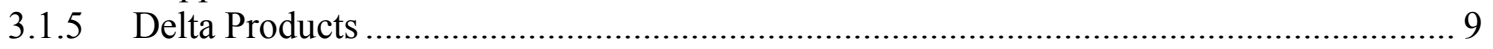

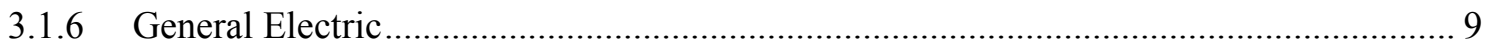

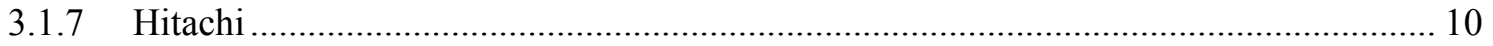

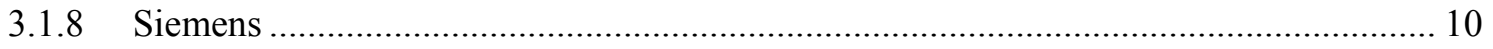

3.2 Utilities, Aggregators, Plug-in Electric Vehicle Manufacturers, and Plug-in Electric Vehicle

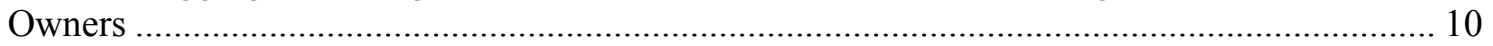

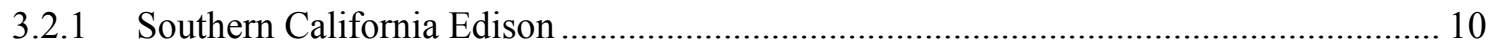

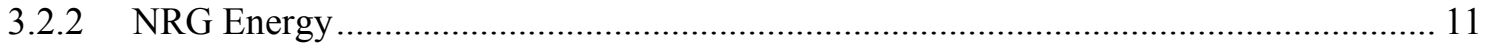

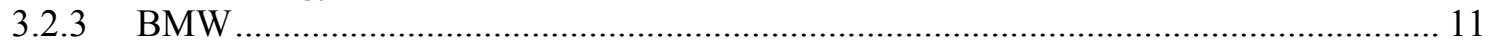

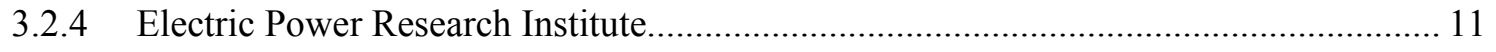

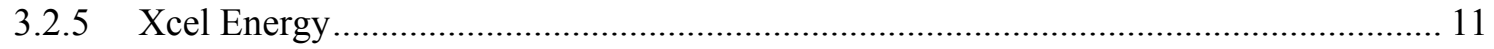

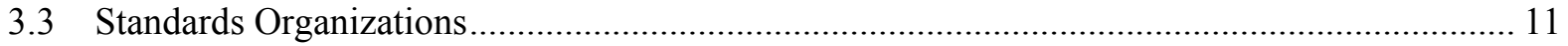

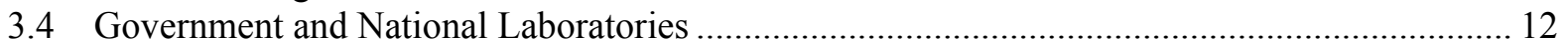

4 Use Cases for Transactive Control of Electric Vehicle Supply Equipment.................................. 13

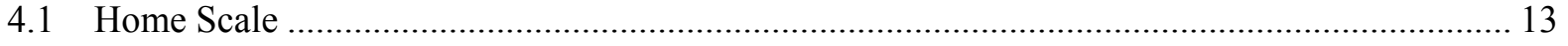

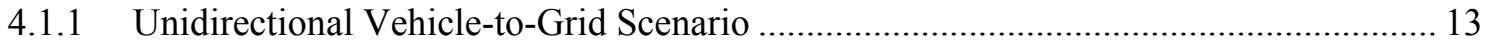

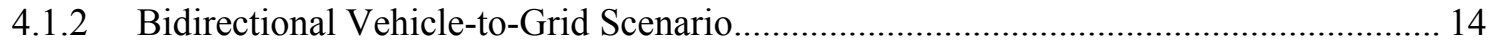

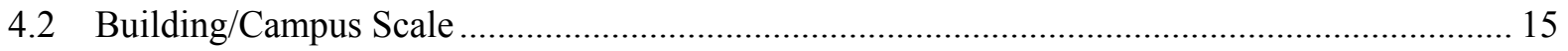

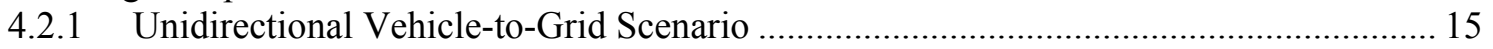

4.2.2 Bidirectional Vehicle-to-Grid Scenario................................................................. 17

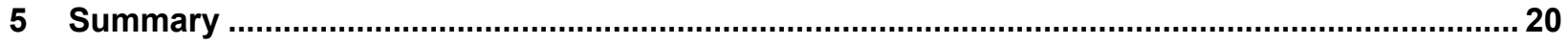

5.1 Barriers to Transactive Control of Electric Vehicle Supply Equipment …................................ 22

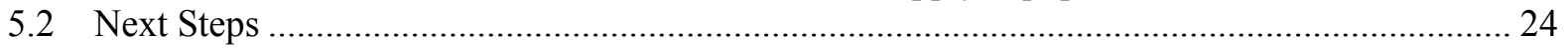

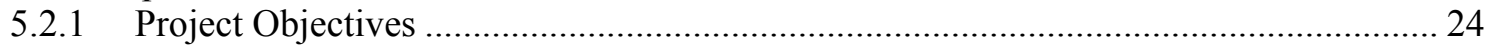

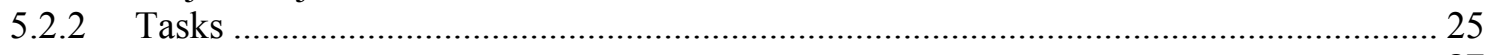

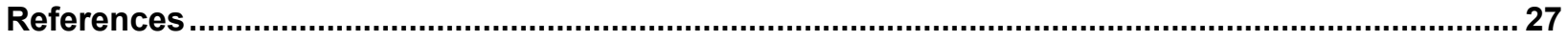




\section{List of Figures}

Figure 1. Nissan LEAFs connected at their home EVSE units during regular weekdays with overnight charge energy [17]

Figure 2. NREL parking structure EVSE charging with campus load information and peak EVSE power. In the graph on the left, the left Y-axis (Power [kW]) applies to the EVSE load and the right Y-axis (Power [megawatt]) applies to the campus load and campus net load...

Figure 3. A block diagram illustrating challenges and opportunities for transactive control of EVSE...... 22

\section{List of Tables}

Table 1. Charging Configurations in Major EV Charging Standards ................................................... 2

Table 2. Major Categories of Services Provided by Transactive Control of EVSE ............................... 21

Table 3. Key Barriers to Transactive Control of EVSE and Strategic R\&D Opportunities [17].............. 23

Table 4. Potential Needs of EVSE Stakeholders and Corresponding Actions [17] .................................25

Table 5. Proposed Tasks for Overcoming Barriers to Transactive Control of EVSE................................ 26 


\section{Introduction}

Deep integration of electric vehicle supply equipment (EVSE) with a power grid offers the potential to provide various types of revenue-generating services for utilities, buildings, and vehicle owners. Despite the rapid increase in the number of EVSE units, many still lack the communication and control capabilities that are needed for effective integration.

Transactive control offers a solution for grid-EVSE integration. It may enable market-driven approaches to coordinate vehicle charging in residential communities and commercial charging centers. Local markets could be designed to offer value simultaneously to utilities, EVSE owners, and vehicle drivers by incorporating demand charges, flexible queueing configurations, renewable energy sources, and additional third-party services.

The EVSE industry is evolving rapidly as vehicle range, battery technology, and equipment standards advance. This report characterizes some opportunities and challenges that arise in developing a transactive control strategy for effective grid-EVSE integration in various use-case scenarios in a way that provides end-user, energy market, grid, and societal benefits.

The objectives of the report are to serve as a reference guide for stakeholders in the grid-EVSE integration area, illustrate potential implementations, and identify a high-value research project for overcoming the barriers and unlocking the benefits of transactive controls of EVSE. While it is not intended to specify the technical details of the transactive control solution, the report contains a list of use cases describing potential applications of transactive control of EVSE, barriers to implement these applications, and research and development (R\&D) opportunities to overcome the barriers. 


\section{Background on EVSE and Transactive Control}

A plug-in electric vehicle (PEV) uses electric energy stored in rechargeable battery packs from an external source. PEVs include all-electric vehicles (also called battery electric vehicles, or BEVs) and plug-in hybrid electric vehicles (PHEVs). As of today, more than 20 automakers have introduced PEVs to the market. Examples include Nissan's all-electric LEAF (85-mile range and 24-kWh battery pack), Tesla's all-electric Model S (265-mile range and 85-kWh battery pack), and Chevrolet's PHEV Volt (38-mile electric range and 16.5-kWh battery pack) [1]. The emerging PEV market has fueled the growth of the EVSE industry. Also known as an electric vehicle (EV) charging station or electric recharging point, an EVSE unit is infrastructure that supplies electric energy for PEVs.

\subsection{Essentials of Electric Vehicle Supply Equipment}

Alternating current (AC) and direct current (DC) charging technologies have been widely adopted in EVSE. AC charging is used in residential and commercial applications, whereas DC fast charging is used only in commercial applications because of its higher requirements on the distribution infrastructure [2]. Both $\mathrm{AC}$ and $\mathrm{DC}$ charging technologies convert AC power to DC power; the only difference is where the conversion occurs. AC charging converts the power onboard the PEV, whereas DC charging converts the power on the EVSE. Based on the charging capacity, AC charging consists of two segments: AC Level 1(120 Volt, 16 Amp peak) and AC Level 2 (240 Volt, 80 Amp peak). These are the only two AC standards that are established and practiced in North America. The most common DC charging technology is DC Level 2, which is an established standard in Japan and is also practiced in North America. The Japanese DC standard is challenged by the proposal of a competing DC Level 2 standard by the North American auto industry [3]. Table 1 summarizes the configurations in major electric vehicle (EV) charging standards and the following paragraphs provide details of these standards.

Table 1. Charging Configurations in Major EV Charging Standards

\begin{tabular}{l|l|l|l|l|l}
\hline Standard & Charging Level & Connector & Voltage (Volt) & Current (Amp) & Power (kW) \\
\hline SAE J1772 & AC Level 1 & J1772-2009 & 120 & $\begin{array}{l}12 \text { (typical) } \\
16 \text { (peak) }\end{array}$ & $\begin{array}{l}1.44 \text { (typical) } \\
1.92 \text { (peak) }\end{array}$ \\
\hline SAE J1772 & AC Level 2 & J1772-2009 & 240 & $\begin{array}{l}15,30 \text { (typical) } \\
80 \text { (peak) }\end{array}$ & $\begin{array}{l}3.6,7.2 \text { (typical) } \\
19.2 \text { (peak) }\end{array}$ \\
\hline SAE J1772 & DC Level 1 & $\begin{array}{l}\text { J1772 } \\
\text { Combo }\end{array}$ & $200-450$ & 80 (peak) & 36 (peak) \\
\hline SAE J1772 & DC Level 2 & $\begin{array}{l}\text { J1772 } \\
\text { Combo }\end{array}$ & $200-450$ & 200 (peak) & 90 (peak) \\
\hline CHAdeMO & DC & JARI/TEPCO & 500 & 12.5 (peak) & 62.5 (peak) \\
\hline
\end{tabular}

The Society of Automotive Engineers (SAE) has established a North American standard, SAE J1772, which defines the operational requirements and the functional and dimensional requirements for the J1772-2009 connector [4]. Two charging levels have been defined in the SAE J1772 standard: AC Levels 1 and 2. AC Level 1 charges a PEV at 120 Volts AC with 16Amp peak current, which may be directly provided by a single-phase household socket. Because of the low charging capacity and the prolonged charge times at AC Level 1, many PEV owners are interested in AC Level 2 charging to improve vehicle availability. AC Level 2 charges a PEV 
at 240 Volts AC with 80-Amp peak current, although most PEVs are designed to accept no more than 30 Amps [1]. The AC to DC power conversion for AC Level 1 and Level 2 takes place onboard the PEV. The EVSE acts as a cord to connect the vehicle with either a standard socket or a hardwired connection to a distribution panel. The EVSE features an internal breaker to ensure that the connector is not energized until communication with a PEV has been established. The charging time depends on the capacity of the onboard charger and the battery's state of charge. To fully charge its 24-kWh battery pack, a Nissan LEAF connected to an AC Level 2 EVSE requires up to 8 hours for a $3.3-\mathrm{kW}$ onboard charger or up to 4 hours for a $6.6-\mathrm{kW}$ onboard charger.

A DC fast charger converts AC power to DC power offboard. Five PEVs are compatible with DC fast charging: two with the CHAdeMO standard (Nissan LEAF and Mitsubishi i-MiEV), two with the SAE Combined Charging Standard (Chevrolet Spark EV and BMW i3) and one with proprietary connector (Tesla Model S) [2]. CHAdeMO is a DC fast-charging standard developed by the Japanese auto industry. CHAdeMO-compatible EVSE delivers up to $62.5 \mathrm{~kW}$ (500 Volts DC and 12.5 A) of high-voltage DC via JARI/TEPCO connectors [5]. A Nissan LEAF with a DC Level 2 charger takes less than 30 minutes to fully charge. After evaluating the JARI/TEPCO connector design [6], the SAE J1772 committee has also proposed a DC connector for DC Level 1 (up to $36 \mathrm{~kW}$ ) and DC Level 2 (up to $90 \mathrm{~kW}$ ). The SAE DC Level 3 specification has not been determined. SAE developed a Combined Charging Standard that defines a variant of the J17722009 connector with additional pins to accommodate DC fast charging at Level 2 power. The new connector enables the communication between the vehicle, offboard charger, and smart grid by using power line carrier technology [7]. Another common example of a DC fast charger is Tesla's proprietary Supercharger [8]. The latest Supercharger delivers $120 \mathrm{~kW}$ output and charges the $85-\mathrm{kWh}$ battery pack of a Model S from $10 \%$ state of charge to $80 \%$ state of charge in 40 minutes. Tesla also offers an SAE J1772 adapter for charging with AC Level 2 EVSE.

\subsection{Electric Vehicle Supply Equipment Market Trend}

EVSE infrastructure is divided into the following market segments: commercial (including public, private, and workplace) and residential. Public EVSE units are charging stations any PEV owner can access for free or for a charging session fee. Private EVSE units provide limited access for a select group such as fleets or residents of a multifamily building. Workplace EVSE access is limited to employees of the company that installed the charging equipment. Residential EVSE units are installed at PEV owner residences and are intended for personal use only [2].

Much of the public infrastructure available today in the United States was developed under the ChargePoint America [9] and EV Project programs [10] supported by federal government funding. About 12,000 AC Level 2 and 100 DC Level 2 EVSE units have been deployed under the EV Project. More than 4,700 residential and public AC Level 2 EVSE units have been installed under the ChargePoint America program [11]. With the completion of these two programs, the public EVSE proliferation is now largely dependent on either private investment or state and local funding support [2]. States are beginning to decouple EV charging from utility regulation; utilities such as NRG Energy, Austin Energy, and CPS Energy are developing business models for their own networks [12]. Besides the public installations, about one-third of the commercial EVSE installations are private. Most commercial EVSE units are AC, probably because a limited number of PEV models are compatible with DC fast-charging infrastructure 
and the cost of a DC fast charger is much higher than an AC charger. The U.S. Department of Energy (DOE) launched a Workplace Charging Challenge in January 2013, aiming to achieve a tenfold increase in the number of U.S. employers offering charging in the next 5 years [10]. DOE provides technical assistance and information resources to participants but does not provide funds for EVSE installations.

Data on EVSE use from the DOE deployment projects in the second quarter of 2013 indicate the most likely places for charging are homes and workplaces. On average, each home EVSE unit had 0.90 charging events per day compared to 0.57 for the private units and 0.22 for the public units [10]. The public EVSE is most likely to be occupied during regular business hours on weekdays. The peak charging demand occurs in a much smaller window, from around 10 a.m. to noon. On average, a PEV spends 4.5 hours connected to the public charger per charging event, and the time spent actually drawing a charge is only 2.3 hours [12]. This number is a promising sign for retailers who want to attract customers and keep them in the stores by providing charging services; however, the retailers incur additional costs if drivers stay in the parking spots after the charging is complete. Possible solutions include using multiplex chargers or charging a higher fee if the idle time exceeds a certain threshold. The multiplex charger connects to multiple PEVs but charges one PEV at a time. This is an advantage for retailers that have limited power capacity at the distribution transformer and want to provide PEV charging services without upgrading their power distribution equipment.

Price competition in the residential charging market is another key trend in the EVSE market. A Level 2 EVSE unit can add up to $\$ 2,000$ to the cost of a PEV. In 2013, Bosch implemented a new price threshold and triggered a price war in the residential charging market [13] by introducing the \$449 Level 2 Bosch Power Max charger. The Power Max EVSE charges at 3.3 $\mathrm{kW}$ and comes with a 12-ft cord, which makes it more competitive than most Level 1 EVSE units. A typical Level 1 EVSE unit costs about $\$ 700$ and is usually included with a PEV purchase. Level 1 EVSE units will still be attractive for customers who do not have a 240-V outlet available and do not want to pay the installation costs [13].

\subsection{Impacts of Electric Vehicle Supply Equipment on the Power Grid}

EVSE may impact the grid by contributing peak loads and changing the loading patterns of power distribution infrastructure if vehicle charging is not properly coordinated and integrated as part of the larger power system. The first point of impact on the grid from EVSE is the distribution transformer, which is either pole-top or pad-mounted and typically serves 5 to 15 customers. The impacts of EVSE charging load are primarily local; as EVSE charging loads are aggregated to the substation, transmission, and generation segments of the utility infrastructure, the load becomes insignificant compared to the base load [3].

PEV charging at AC Level 1 has negligible impacts on the distribution system because a typical Level 1 EVSE unit consumes only about 1-2 kW. A typical Level 2 EVSE load could reach 6-7 $\mathrm{kW}$ and may double the typical residential power load during the evening peak load hours, when most PEV owners finish their daily commutes and start recharging at home. In a residential community with high PEV penetration, the coincidental peak loads may overload the distribution transformer and reduce transformer service life [3]. 
Grid integration of EVSE can come in the form of organized unidirectional vehicle-to-grid (V1G) charging or bidirectional (V2G) import and export. Grid-connected EVSE can provide V1G services such as peak shaving or load shifting through demand response (DR) or dynamic rate programs. In addition to these services, V2G-capable EVSE units can provide high-value ancillary services, of which the regulation market is the most lucrative. Regulation services aim to maintain the operating frequency of the grid by balancing the load with generation and require a quick-responding generator or storage facility as the dispatch is in the time scale of minutes [3]. The primary reasons for making an EVSE unit V2G-capable are to generate revenue, save on energy costs, and integrate renewables [12].

\subsection{Impact of Electric Vehicle Supply Equipment on Buildings}

Buildings accounted for about $41 \%$ of primary energy use and $71 \%$ of electricity consumption in the United States in 2010 [14]. Buildings play an important role in enhancing grid reliability and renewable energy integration. With advanced sensors and control technologies, buildings could act as dispatchable assets to provide grid services.

Most of EVSE units are located in buildings or connected to the grid through a building's power distribution system. Similar to the vehicle-grid integration, EVSE presents challenges and opportunities to buildings. EVSE units may require a major upgrade of the building's power distribution system; the PEV charging load may be coincidental to the building peak load and incur additional demand charges. However, EVSE also presents new opportunities for providing various types of services. In the unidirectional power flow scenario, building operators can reduce the demand charges by coordinating PEV charging with building peak load and local renewable energy generation. In the bidirectional power flow scenario, EVSE can be used to feed power from PEVs to buildings, which is known as vehicle-to-building (V2B). V2B occurs behind the meter and can provide emergency power and reduce energy cost. The energy costs can be reduced through demand charge reductions, renewable energy integration, and energy arbitrage.

At the home scale, V2B is primarily a service to be used as an emergency backup power source where individually owned PEVs supply power to the home through EVSE units and inverters. Energy arbitrage is more suitable for implementation at the campus scale, where the EVSE unit charges the PEVs at off-peak rates and then discharges power into buildings during on-peak hours. The building/campus operator can also act as an aggregator to perform regulation services with a fleet of PEVs for revenue generation. Fleet vehicles can also be used to power large energy-consuming equipment or grid infrastructure in case of outages [12].

\subsection{Transactive Control}

Transactive control is one part of the transactional energy framework, wherein mutuallybeneficial and cost-effective market-based transactions can be enabled between multiple players across different domains [15]. According to the GridWise Architecture Council [16], the term "transactive" comes from considering that decisions are made based on a value, which is analogous to or literally economic transactions. 
The formal definitions of "transactive control" and related terms are listed below [15]:

- Transaction: The negotiated exchange of products, services, and rights within a structured or unstructured market that enables allocation of value among all parties involved (known as settlement).

- Transactive control (or transaction-based control): A means of executing transactions through automatic control of the operating state of equipment and other energy systems in response to data and value streams.

- Transactive energy (or transaction-based energy): A structure that combines information, data and energy infrastructure to enable energy-based transaction.

- Transactive energy services (or transaction-based energy services): Services that balance all parties' energy needs against available resources, thereby making at least one individual better off without making any other individuals worse off.

An agent-based system is well suited for transactive control because frequent interactions occur between various building components. An agent-based system is composed of multiple interacting agents, which are autonomous, self-aware, and able to communicate with each other to enable coordinated control [17]. Examples of agent-based systems for transactive control include VOLTTRON [18], OGEMA [19], and flexible power application infrastructure [20].

Transactive control is related to, but distinct from, the concept of agent-based control. Agentbased control refers to methods that control agents' collective behavior via a limited number of inputs. Transactive control can be considered as a special type of agent-based control for agentbased systems where the agents are able to perform transactions. The interactions between agents in the agent-based control are not necessarily transactive.

The basic properties that define a transaction include exchangeable products/services/rights, transacting parties, monitoring/regulating entity, process for agreeing on a transaction, contract for terms and conditions, financial settlement and means of payments, etc. [15].

The participants of a transaction may either directly negotiate to reach a consensus (i.e., negotiation) or may use the services of an arbitrator to do so (i.e., auction). For example, a BEV owner arrives at a parking garage and is low on battery. The BEV owner needs to charge the $\mathrm{BEV}$ as soon as possible to prepare for a scheduled departure in several hours, but all the EVSE units are occupied. The BEV owner finds a current EVSE user who is willing to delay the charging. The BEV obtains an earlier charging position and the EVSE user receives a financial compensation. This is known as negotiation. Assuming the garage has a communication platform where the BEV owner can post a request and the current EVSE users can submit their bids, the platform will choose the EVSE user who offers the lowest bid and coordinate the exchange of charging position. This transaction is known as auction. Typically negotiation requires fewer resources for a transaction, whereas the auction is easier to scale up because it avoids direct conversions between willing participants. 
Transactive control enables market-based coordination to optimize energy efficiency and reduce energy costs, energy use, and emissions. It provides energy and energy-related products, services, and rights that

- Balance and co-optimize end-users' overall costs, comfort and convenience

- Support enhanced grid planning, operations and metering

- Bring societal benefits to all involved or affected parties.

A transaction-based framework [15] has been proposed to improve building energy efficiency and energy-savings potential to benefit building owners and operators. Because most EVSE units either reside in buildings or are connected to buildings, this report focuses on the application of transactive control in the context of buildings. Section 4 discusses several transactive control scenarios for EVSE at both home scale and campus scale. 


\section{Stakeholder Activities in Grid-Electric Vehicle Supply Equipment Integration}

EVSE stakeholders include EVSE manufacturers, EVSE owners, PEV manufacturers, PEV owners, utilities, aggregators, standards organizations, governments, and national laboratories. This section describes a nonexhaustive but representative set of the stakeholder activities on grid-EVSE integration, which pave the way for transactive control of EVSE.

\subsection{Electric Vehicle Supply Equipment Manufacturers}

The key EVSE manufacturers in the United States, many of which are actively pursuing the concept of grid-connected EVSE, are listed in a Navigant Research report [12]. Many of these EVSE manufacturers are developing grid communication and control capabilities that follow established interoperability standards such as Smart Energy Profile 2.0. Some of them have pilot programs underway with local utilities to incorporate DR programs or even ancillary services programs. Although there are still some gaps to implementing transactive control on the current EVSE, the entire sector is moving in the right direction. Brief summaries of their work are provided in Sections 3.1.1 to 3.1.8.

\subsubsection{AeroVironment}

AeroVironment [21] offers Level 2 AC home charging stations that are compatible with the SAE J1772 standard and high-voltage DC fast charger that are compatible with the CHAdeMo standard. Nissan selected the company to supply Level 2 AC chargers and installation services for the LEAF. AeroVironment has partnered with government agencies and private sector organizations to deploy EVSE units in many regions, including Oregon, Washington, California, Massachusetts, Hawaii, Texas, and Quebec. The company's EVSE-RS+ model offers grid communication capabilities via cellular or Wi-Fi network communication modules and provides connectivity for up to three optional communication modules.

\subsubsection{Broadband TelCom Power, Inc.}

Broadband TelCom Power, Inc. [22] started to develop battery charging products for materials handling and EV applications in 2006. The company's recent product line includes ground station charging equipment, DC fast chargers, Level $2 \mathrm{AC}$ chargers, a payment technology, and DR systems. More than 5,000 charging payment systems that include Web-based management software have been deployed on the West Coast. Broadband TelCom Power's Level 2 AC charger is equipped with SAE J1772 connector, and its DC fast charger has both SAE J1772 and CHAdeMO connectors. The company plans to develop a high-power, high-efficiency bidirectional DC-to-DC converter to source low-voltage power from renewable energy sources and deliver higher voltages to EVSE. It also plans to develop a bidirectional DC-to-AC inverter system, equipped with controller area network communication and power line carrier modules, to improve grid stability and provide V2G functions. The company has been working with Southern California Edison to develop Smart Energy Profile 2.0-enabled networked EVSE unit to incorporate time-of-use (TOU) pricing.

\subsubsection{ChargePoint}

ChargePoint [23] has more than 20,000 public chargers and is one of the largest network providers of EVSE units. The company began by selling and leasing charging stations to 
organizations that operate parking lots (large retail, workplaces, apartment complexes), but its business model focuses on providing subscription-based networked cloud services, including those for charging stations made and sold by other companies. As a starting point, the services are designed for customer satisfaction (e.g., a mobile application that lets drivers know whether a charging station is available or occupied) and leverages social networking to enhance user convenience. Recently ChargePoint announced its entry into the residential space: the new ChargePoint Home uses a standard 240-V outlet and J1772 connection and works with a Nest thermostat so that the homeowner can participate in the "Rush Hour Rewards" program. The company has also partnered with SunEdison (plans are underway to offer free chargers with residential photovoltaic [PV] purchases) and is looking to collaborate with manufacturers of other home products such as home security systems. At the 2015 Washington Auto Show, BMW, Volkswagen, and ChargePoint announced an initiative to create EV express charging corridors on the East and West Coasts. A goal of nearly 100 DC fast chargers will be installed to support long-distance and metropolitan EV travel with the BMW i3, Volkswagen e-Golf, and other EVs, along heavily trafficked corridors on both coasts, supported by Level 2 AC chargers [24].

\subsubsection{ClipperCreek}

ClipperCreek [25] has a long history of providing charging equipment to utilities and automakers globally. In 2010, ClipperCreek formed a partnership with automotive supplier Delphi to develop charging equipment for the new wave of commercial PEVs. ClipperCreek reports that it has shipped more than 15,000 Level 2 EVSE units since 2009. However, ClipperCreek does not offer DC charging. The company focuses on providing competitively priced automotive-certified EVSE units that do not rely on proprietary networks. ClipperCreek also offers a commercial smart grid-enabled EVSE and has deployed more than 650 units. The company has a pilot underway with the Sacramento Municipal Utility District, which is testing a smart gridnetworked EVSE unit that is controlled by the utility. The company is also just completing a smart grid solution with Itron and will deploy it in a number of pilots with major utilities in the next 12 months. ClipperCreek also has a smart grid solution with Silver Spring Networks that has limited deployment [12].

\subsubsection{Delta Products}

Delta Products teamed with DTE Energy to demonstrate its new smart EV charging technology. With communication capabilities and a site management system, Delta's smart grid-connected EVSE unit can prioritize and optimize the operations of a group of EV workplace charging stations based on utility energy profiles. This new system allows utilities to manage loads during peak hours and will help drivers save money by taking advantage of off-peak power rates. Delta deployed 24 smart grid-capable EVSE units in the MGM Grand parking garage adjacent to DTE Energy headquarters, making it the largest cluster of smart grid-connected charging stations in Michigan. DTE employees and MGM Grand guests may use the chargers. Delta plans to show by the end of 2015 how clusters of charging stations can be reliable adjuncts to the electricity grid [26].

\subsubsection{General Electric}

General Electric offers Level 2 units for residential and commercial applications, with networked and nonnetworked commercial units for the United States and Canada. Its portfolio does not 
include Level 1 or DC charging equipment. General Electric's networked WattStation is cloudbased. The nonnetworked stations can be connected to a local network to allow local management of users. The WattStation supports MODBUS [27]. The company has mentioned the possibility of integrating its Nucleus home energy management product with the WattStation, which could provide an advantage in managing consumers' overall energy consumption [12].

\subsubsection{Hitachi}

Hitachi manufactures 50-kW DC fast charger. It is currently being sold in Japan and recently received Underwriters Laboratories certification so that it can be sold in the United States. The company offers CHAdeMO chargers and is considering offering SAE combo chargers. The company is participating in the JUMPSmart Maui project, where it is connecting $20 \mathrm{DC}$ fast chargers to the local power grid so that it can respond to grid signals and assist in DR and ancillary services programs [28]. In 2014, the company began using the equipment in V2G demonstrations [12].

\subsubsection{Siemens}

Siemens recently teamed with Ford, Duke Energy, and University of California-Irvine to develop smart grid-capable EVSE units for residential applications. The project aimed to redesign Siemens' Level 2 residential charging station and deploy a smart load management system to minimize the residential and utility infrastructure upgrade cost. The improved Siemens residential Level 2 EVSE, called VersiCharge SG, is equipped with Smart Energy Profile 2.0enabled ZigBee and Wi-Fi modules, a USB host port for customer-specific communication in the future, and HomePlug Green PHY power line carrier. Siemens used distributed control algorithms to establish a cloud service platform to manage EV loads and still maintained or improved power quality, reliability, and affordability. Siemens plans to conduct a compliance test at Argonne National Laboratory (ANL), a cybersecurity study at Idaho National Laboratory, and a demonstration at Duke Energy Envision Center [29].

\subsection{Utilities, Aggregators, Plug-in Electric Vehicle Manufacturers, and Plug-in Electric Vehicle Owners}

Utilities and aggregators are actively working with PEV manufacturers, EVSE manufacturers, and PEV owners to roll out pilot projects and programs to study the impacts of EVSE on the power grid and potential opportunities for vehicle-grid integration (VGI). Utilities and aggregators are particularly interested in effective management of EVSE such that the charging load does not add to the existing peak load. Some utilities are launching V2G programs where PEVs can provide grid services through EVSE and receive financial compensations. These are the prototypes of a transactive energy market. Several examples are described in Sections 3.2.1 to 3.2 .5 .

\subsubsection{Southern California Edison}

Southern California Edison worked with Greenlots to conduct a DR load control-enabled workplace charging pilot using OpenADR 2.0b with dynamic pricing. Seventy Level 2 EVSE units can be curtailed to Level 1 with dynamic pricing at the point of sale across eight Southern California Edison properties. Greenlots is a California-based company that provides networked solutions for EVSE management [30]. 


\subsubsection{NRG Energy}

NRG Energy launched the "eVgo" network in late 2010, the first privately owned and publically accessible car-charging station network for PEVs. NRG set up a partnership with the University of Delaware to fund V2G programs. In 2013, the University of Delaware and NRG became official resources of the Pennsylvania-New Jersey-Maryland Interconnection with 15 PEVs at $100 \mathrm{~kW}$ and demonstrated for the first time that V2G technology can earn revenue by participating in the Pennsylvania-New Jersey-Maryland frequency regulation market. NRG and the University of Delaware are also working with Honda and BMW to build prototypes for V2G demonstration [31].

\subsubsection{BMW}

BMW is working with California-based Pacific Gas and Electric Company (PG\&E) to launch the BMW i ChargeForward Program. The program aims to reduce the impact of EV charging on the grid and supports renewable energy integration. The program invites BMW i3 owners, who are also PG\&E customers in the Bay Area, to participate in the 18-month pilot program. The program will manage the home charging of participating BMW i3 vehicles, delaying the charging of some vehicles by up to 1 hour based on signals provided by PG\&E. The drivers can opt out of participation 1 day at a time throughout the program. A stationary battery storage system composed of used MINI E vehicle batteries is used to meet the EV charging needs and reduce the grid load. Participants will receive gift cards at the beginning and the end of the pilot program [32].

\subsubsection{Electric Power Research Institute}

The Electric Power Research Institute is working with 8 automakers and 15 utilities on an Open Vehicle-Grid Integration Platform program to integrate PEVs with smart grid technologies that enable utilities to support PEV charging regardless of location. The platform will allow manufacturers to offer a customer-friendly interface through which PEV drivers can more easily participate in utility PEV programs, such as rates for off-peak or nighttime charging. The portal for the system would be a utility's communications system and a PEV's telematics system [33].

\subsubsection{Xcel Energy}

Xcel Energy offered its Colorado customers an Electric Vehicle Charging Station Pilot that was carried out from summer 2013 through summer 2014. The pilot was designed to explore the possibility for PEV owners and Xcel Energy to minimize the load on the grid during peak times. Xcel Energy installed control modules in series with the participating customers' Level 2 EVSE units and communicated wirelessly with the control module to interrupt power during "control events." Xcel Energy was allowed to initiate control events up to 12 times per year during weekdays between 2 p.m. and 6 p.m. and sent customers 1-hour notices before an event. In return, each participating customer received a $\$ 100$ annual utility bill credit [34].

\subsection{Standards Organizations}

SAE is developing a new standard, SAE J3072: Interconnection Requirements or Onboard, Utility-Interactive, Inverter System. The standard is being created to ensure a PEV onboard inverter system can be safely connected in parallel with an electric power system by way of the EVSE unit [35]. An onboard inverter system can enable the V2G capability of a PEV and increase the PEV's capability to provide grid services. 


\subsection{Government and National Laboratories}

The National Renewable Energy Laboratory (NREL) is currently leading the Vehicle Technologies Office sponsored Multi-Lab Smart Grid Requirements Study, under the INTEGRATE activities, which is an initiative to find areas of focus for VGI to enable increased adoption of PEVs. This activity leverages the expertise across the national laboratories with collaboration from ANL, Idaho National Laboratory, Lawrence Berkeley National Laboratory, Oak Ridge National Laboratory, and Pacific Northwest National Laboratory (PNNL). NREL is using the NREL parking structure, which contains 36 Level 2 EVSE units, to collect charging energy information in a commercial building environment.

NREL has actively participated in the Smart Power Infrastructure Demonstration for Energy Reliability and Security, which focuses on developing a semiautonomous microgrid to provide electric power surety. The V2G part of the project is a demonstration of how PEVs can support the microgrid by providing energy storage. One objective of the demonstration is to develop hardware and software to interface PEVs to an electrical microgrid and aggregated control system. The demonstration also aims to control the bidirectional inverters with connected PEVs to provide peak power shaving, frequency regulation, and reactive power while the microgrid is in grid-tied mode [36].

PNNL has demonstrated an application of residential load management using VOLTTRON ${ }^{2}$, which is an open source agent-based control system. The goal is to maintain the total energy usage of a residence at a defined goal in spite of large transient loads such as a heating, ventilating, and air-conditioning (HVAC) unit, three charging stations, and a water heater. Neither the water heater nor the HVAC is controlled by the VOLTTRON agents. The VOLTTRON agents control EVSE charging rate and fulfill all homeowner energy demands by carefully specifying energy consumption priorities [18].

ANL developed a DC-charging digital communication controller, the Smart Grid EV Communication module, which can be integrated into DC chargers or PEVs to establish SAE DC charging communication. Using an offboard charger requires a digital communication link between the battery energy control module and the offboard charger. The Smart Grid EV Communication serves as the interface for PEV-EVSE communication [37].

Lawrence Berkeley National Laboratory is working with the U.S. Department of Defense on two ongoing vehicle grid integration demonstrations that are designed to use managed vehicle fleets to provide grid services to the wholesale market in California. The demonstrations are at the Los Angeles Air Force Base and at the U.S. Army Reserve 63rd Regional Support Command. The U.S. Department of Defense has targeted grid services as a way to decrease the overall cost of operating the vehicle fleet. The Los Angeles Air Force Base fleet will provide a V2G service, frequency regulation, to the California Independent System Operator wholesale electricity market. The fleet consists of a mix of PHEVs and BEVs that can charge and discharge via AC Level 2 and DC fast-charging interfaces. OpenADR 2.0b, Open Charge Point Protocol, and Smart Energy Protocol 2.0 will be used for communicating DR commands in the demonstration. The 63rd Regional Support Command demonstration is similar to the Los Angeles Air Force Base demonstration, but will use the V1G structure only [17].

\footnotetext{
${ }^{2}$ VOLTTRON is a freely available agent-based platform developed by PNNL. It can be downloaded from http://gridoptics.pnnl.gov/VOLTTRON/.
} 


\section{Use Cases for Transactive Control of Electric Vehicle Supply Equipment}

Some of the EVSE units in the present market are able to communicate with their back offices in order to verify the user is an authorized user of the service. This communication capability has not been focused on controlling power and energy use to meet grid integration objectives. Implementing EVSE units with grid control and communication capability would enable a building management or other agent software to control PEV charging in a more organized - and possibly better managed - environment. The charging would provide benefits at the building/campus and home scales and participate in "behind the meter" grid services. These PEVs could also be aggregated into a large group to provide grid services. This section discusses a few use cases in V1G and V2G scenarios at the building/campus and home scales. While the section is not intended to prescribe specific solutions, it contains a list of use cases describing a range of possible applications of transactive control with the underlying assumptions.

\subsection{Home Scale}

\subsubsection{Unidirectional Vehicle-to-Grid Scenario}

At the home scale in a V1G scenario, the PEV could be used to manage energy costs by shifting charge time to take advantage of TOU rates. The PEV capabilities at the home scale need to be understood in the context of how and when these PEVs are connected to their home chargers and the energy needs associated with providing their primary role of transportation. In Figure 1 [17], data have been analyzed from the EV Project data collected from October 2012 to October 2013 for 430 privately owned Nissan LEAFs in the Seattle area.
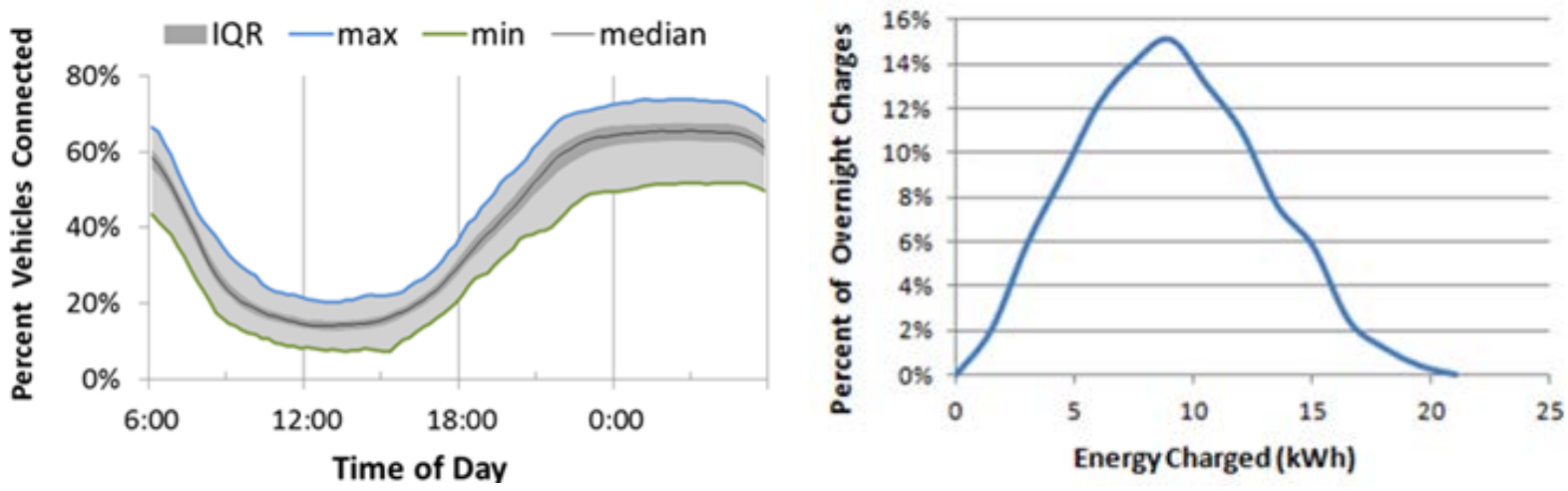

Figure 1. Nissan LEAFs connected at their home EVSE units during regular weekdays with overnight charge energy [17]

The graph on the left of Figure 1 is an analysis of when the LEAFs are plugged into their home chargers during regular weekdays, excluding holidays. This representation is consistent with the EV Project [10] data for LEAFs in other regions and should be thought of as typical at-home plug-in behavior. The number of connected LEAFs in the middle of the day is approximately $20 \%$; at night the number reaches only $65 \%$ at about 10 p.m. because some vehicles are not plugged in every night. The graph on the right of Figure 1 is a distribution that represents the amount of energy required for all overnight charges during the collection period to complete the charge of the vehicles that have been connected to their home chargers. These data show that most LEAFs need 5-15 kWh of energy to complete their nighttime charge. This analysis focused 
on home charging with a Level 2 EVSE unit to understand the consistency of home EVSE connectivity and the required energy to maintain the primary mobility requirement of the vehicles. These data are helpful in understanding the home-scale opportunities. Several V1G use cases are discussed below.

- Dynamic pricing. EVSE units that can communicate to a load-serving entity would be able to use dynamic rates that could change based on pricing in a day-ahead market or even in real time based on conditions within the transmission and distribution systems. Commonwealth Edison presently has a real-time pricing rate program [38] with integrating home HVAC load management; however, this program does not include implementation of this dynamic pricing signal with an EVSE charging schedule. Currently, the only EVSE implementation has been with TOU rates in which fixed rates are published in a rate program. These rates vary by day of the week, time of day, and in some cases by season [39]. In this scenario, the PEV has a control interface in which the owner can program a fixed charging schedule to use the lower rates. The data from the EV Project suggest that from 10 p.m. to 6 a.m. nearly all vehicles that will be plugged in for an overnight charge are connected. This provides approximately a 8-hour window to schedule the approximately 3.5 hours (at $3.3 \mathrm{~kW}$ with charging taper time considered) needed to meet the median energy use of about $10 \mathrm{kWh}$.

- Local renewables integration. The highly dynamic nature of the onboard chargers in PEVs could allow renewable generation to reduce energy cost or to overcome the limitations of non-net-metered installation. This, however, might provide only modest benefit to those with rooftop PV installations, given that the EV Project data indicate that only about $20 \%$ of PEVs are connected to their home EVSE units during the middle of the day.

- Distribution capacity deferral. Adding multiple PEVs to a local distribution transformer at the home scale could represent considerably more load than was intended in the original design of the neighborhood distribution system. In these systems, a 25$\mathrm{kVA}$ transformer is commonly used to serve the load of five to seven homes; therefore, adding a Level 2 EVSE (assuming a PEV with a 6.6-kW onboard charger) could be the equivalent of adding one house load to the transformer [40]. The cost of replacing these transformers could be deferred through coordinated charging of the PEVs behind the transformer through a transactive control method. Initially this deferral could be effected through TOU pricing; however, as adoption increases, additional issues could be presented if a large number of PEVs are programmed to begin charging in the same time windows.

\subsubsection{Bidirectional Vehicle-to-Grid Scenario}

In a V2G scenario, a PEV can provide energy to the grid through either a bidirectional onboard charger or a DC connection to an EVSE unit that contains a stationary inverter. These differ from V1G scenarios because they add more cycling to the PEV battery pack. Furthermore, PEVs without DC connections to EVSE units require modification to the onboard charging hardware presently available on all original equipment manufacturer PEVs for bidirectional functionality. In addition, even the PEVs with DC connections require changes in their control software to allow DC discharge. The associated cost of the increased cycling and the additional hardware would need to be understood when considering these scenarios. 
- Energy arbitrage. Energy could be provided to a home from a PEV in an effort to reduce the energy cost for operating the home in a dynamic pricing environment. This would likely be an effort to offset the typical high-demand period of the grid around 6 p.m. and recharge the vehicle at the lower nighttime electricity rate. The data from the EV Project show that around 6 p.m. about $30 \%$ of PEVs are connected to their home EVSE units. If the energy required for an overnight charge is assumed to be uniformly distributed with time of connection, only an additional $25 \%$ of this group of PEVs (which require a charge of $5 \mathrm{kWh}$ or less according to Figure 1) would apparently have about 15 $\mathrm{kWh}$ of available energy ( $24 \mathrm{kWh}$ battery pack charged at $80 \%$ subtracts $5 \mathrm{kWh}$ ) to provide for use in arbitrage. These PEV owners may still expect that a reserve of energy is maintained for unexpected trips.

- Critical load support. The market for emergency generators to provide power during a grid outage represents an interesting application for V2G capability. Outage support could possibly be provided to the critical loads of the home that is using the energy in the PEV. The unexpected nature of a grid outage might support this capability for PHEVs only, because ensuring that BEVs maintain enough reserve energy throughout the day for uncertain contingency scenarios would be difficult.

\subsection{Building/Campus Scale}

\subsubsection{Unidirectional Vehicle-to-Grid Scenario}

At the building scale in a V1G scenario the increase in number of PEVs, such as at a parking structure, provides for an expanded set of use cases over those possible at the home scale. The data from Figure 2 were collected during 2014 at the NREL parking structure, which contains 36 Level 2 EVSE units. At the end of 2014, 50 employees were registered users of these chargers.
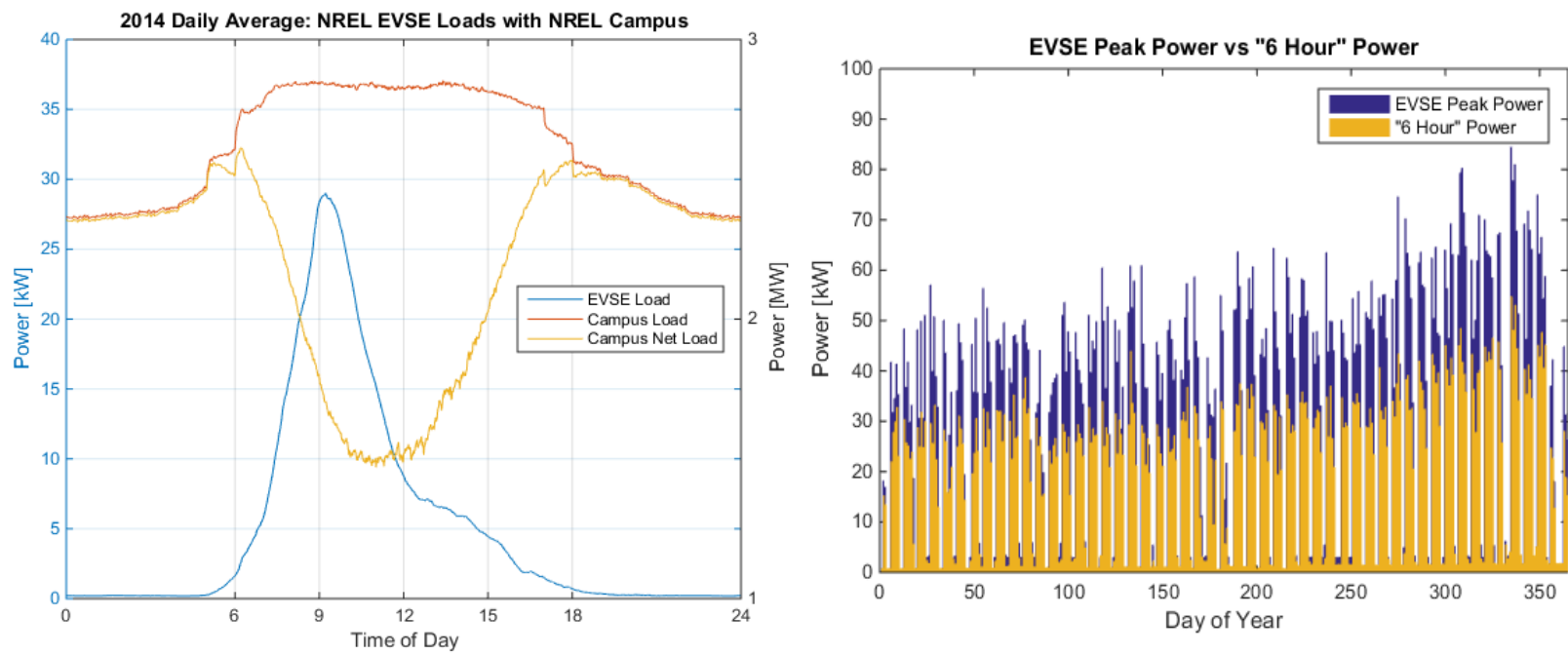

Figure 2. NREL parking structure EVSE charging with campus load information and peak EVSE power. In the graph on the left, the left Y-axis (Power [kW]) applies to the EVSE load and the right $\mathrm{Y}$-axis (Power [megawatt]) applies to the campus load and campus net load.

The graph on the left of Figure 2 shows the average daily EVSE load, campus load, and campus net load during normal workdays. This graph demonstrates that with uncontrolled charging most of the PEVs are charging in the morning following their arrival and plug-in. The net load shows 
the effect that the PV installations on campus have on reducing the net load throughout the middle of the daylight hours. This primarily moves the peak demand on campus to the early morning hours. The graph on the right of Figure 2 provides the peak power demand from the EVSE, based on the average power over a minute duration, for every day in 2014 . The "6-hour" power represents the amount of power that would have been drawn by the EVSE if the energy for the entire day was provided uniformly over a 6-hour window. This "6-hour" power demonstrates that all charging could be moved into a window from 9 a.m. to 3 p.m. when the PV installations typically provide the most energy. Although these data may not be characteristic of all such building/campus scenarios (e.g., a considerable amount of PV power on campus and a relatively flat campus load), they do help to illustrate several opportunities.

- Charging capacity deferral. Controlled charging can be used to reduce the cost of EVSE installation through capacity deferral by planning and managing charge times. PEVs are typically at workplace parking structures for many more hours than are needed to complete a charge. This control would require additional information from the drivers to determine when they plan to depart and how much energy is required to transport them to their next charging opportunity. Data collected at the NREL parking structure illustrate that for the number of PEVs that use the facility, only $55 \mathrm{~kW}$ would have been needed to meet the highest energy demand day, whereas on that particular day the peak load with uncontrolled charging was $85 \mathrm{~kW}$. At this level of deployment the capacity (transformer and distribution connection) requirement differences would not make a considerable cost difference; however, in larger deployment scenarios the approximately one-third reduction could be significant.

- Peak demand reduction. Controlled charging could be used to ensure that adding the EVSE units at a building/campus does not add to peak demand charges. Typically the cost of the energy charge is very low compared to the demand charges for a commercial customer of electricity. The NREL parking structure example shows that at a minimum, charging could be scheduled such that approximately one-third of the EVSE addition of the demand could be removed. The peak could be reduced further by stopping all charging if the net load at the building/campus were consistent day-to-day and shaped with a pronounced peak and trough such that the charging could be shifted. In the V1G scenario this control reduces only the demand costs for charging because the campus net energy required over the day would not decrease from PEV charging.

- Demand response. PEVs could provide a similar service to the emergency curtailment programs that are designed to turn off nonessential loads such as lighting and HVAC systems during peak demand events [41]. This service is likely to be supported by PEVs at the building/campus scale based on their connection and power use during the middle of the day as shown by the NREL parking structure data. The post-DR period may require more power than would have been needed without the curtailment to complete the charge following the curtailment. The PEV owners would likely still expect their charge energy to be fulfilled to meet their driving requirements.

- Trading positions in a charging queue at a multiplex EVSE. The cost of Level 2 EVSE could be reduced by designing EVSE units that provide multiple charging cords from the same device. This would allow for multiple PEVs to be connected when they are parked and for the PEVs to then share the capacity of the single electrical connection. 
The cost reduction in the EVSE would come from sharing the internal electronics, the housing, and the installation costs of the electrical connection to the distribution panel. However, the cord set and the internal breaker costs would scale with the number of connectors. The limitation of this approach over control at a transformer or distribution connection point is that the connection distribution - in other words, which PEV types (PHEVs/BEVs) are connected to which EVSEs - will influence the performance of the power use optimization and therefore the effectiveness of capacity deferral and peak demand reduction. This may be a more effective solution when retrofitting a parking structure than when installing EVSE at a new facility.

- Monetizing delayed EVSE charging to prioritize fast charging: DC fast chargers can represent a more substantial load of $20-120 \mathrm{~kW}$ to provide charge times of about 30 minutes [8]. These chargers may represent a case where enough financial value is associated with quick departure times to monetize the convenience and require the PEV owner to pay substantially more than the energy costs. This scenario is likely limited to the value difference between a fast charge and the use of gasoline. More specifically, the 2015 Ford Focus achieves 33 miles per gallon and the 2015 Ford Focus EV has a combined electric rating of $32 \mathrm{kWh} / 100$ miles [42]. This means that for a Ford Focus EV owner the value of $10.6 \mathrm{kWh}$ of charge should not exceed the cost of 1 gallon of gasoline. Certainly the BEV owner who needs more range and is otherwise stranded would pay more than the cost for refueling an equivalent gasoline vehicle, but this would challenge the value proposition of owning a BEV. Those with PHEVs would be incentivized to use their gasoline engines instead of fast charging (the PHEVs on the market presently do not have fast charge capability).

This fast-charging scenario would allow for a situation where other PEVs on Level 2 EVSE units could be incentivized to delay their charges to reduce the cost of the peak demand associated with the DC fast charger. The incentives to the PEVs charging on Level 2 EVSE units might be through direct transactive energy costs or indirectly by subsidizing the cost of Level 2 installations (e.g., increasing charger location availability). A considerable number of Level 2 chargers would be required to offset the power of the DC fast charger because three to six PEVs would be required to offset 20 $\mathrm{kW}$ (assuming 6.6-kW and 3.3-kW onboard chargers). Furthermore, these PEVs must otherwise be charging so that their charges can be suspended. Even more installed Level 2 EVSE units would thus be needed to take advantage of this opportunity. In the 36 EVSE examples from the NREL parking garage, referencing the "6-hour" energy data, only $30-40 \mathrm{~kW}$ would apparently be available if the Level 2 EVSE units were controlled to reduce peak demand. Therefore, even in a facility the size of NREL's parking garage, only a single DC fast charger could be supported by delaying the charging of other vehicles.

\subsubsection{Bidirectional Vehicle-to-Grid Scenario}

In a V2G scenario at the building/campus scale, the availability of more PEVs at a single location provides an expanded set of potential scenarios for grid integration. As with V2G at the home scale, the following scenarios would require an understanding of the effects on battery degradation to understand their true value. 
- Ancillary market. The ancillary market generally consists of two services: frequency regulation and synchronized (spinning) reserves [43]. The frequency regulation markets typically require that a resource be able to provide up regulation (discharge to the grid) and down regulation (charge from the grid). In these markets a capacity bid (typically up and down regulation are balanced) is placed for an upcoming time horizon (usually 1 hour) and the resource must, if called upon, be able to provide the capacity for the entire time period. This service is often considered energy neutral, though this may depend on the amount of time a PEV is available to participate. Synchronized reserves are complementary to the concept of DR in that they provide capacity to the grid in times of unexpected high demand. In deregulated markets frequency response can have average values of $\$ 30-\$ 45$ per megawatt-hour for the energy delivered, whereas synchronized reserves can have a value of $\$ 10$ per megawatt-hour of available capacity (power) [44]. These values can be highly influenced by the more recent low natural gas prices and the demand elasticity may be weak in relation to a large number of PEVs participating in this market. The difference in how these resources are monetized reflects frequency regulation as a resource that is often dispatched with frequent changes in power flow direction; however, synchronized reserves are used for contingency purposes and provide their value from the amount of capacity that can be called upon.

PEV participation in the ancillary markets requires a third party, frequently referred to as an aggregator. An aggregator coordinates bidding into the market with multiple PEVs, provides control communication from the grid operator to the PEVs, and is responsible to maintain evidence that the aggregator provided the called-for service. At the building/campus scale, EVSE units with DC fast-charging capability would more likely be viable, meaning that if those chargers were designed to contain bidirectional inverters a single PEV could provide a high-power V2G service. In the short term this is more feasible than developing a robust set of aggregators such that a large fraction of produced PEVs could participate in ancillary markets. This robust set of aggregators would be expected for original equipment manufacturers to change the design of onboard chargers to include bidirectional capability and saddle all PEV purchases with this incremental cost. Furthermore, participation in the Pennsylvania-New Jersey-Maryland market would require that the aggregated group of PEVs be able to provide at least $100 \mathrm{~kW}$ of capacity [45]. At this power 15-30 PEVs would need to participate given the predominant onboard charger power rating of $3.3-6.6 \mathrm{~kW}$. The building scale provides a favorable environment for developing aggregators in which the fixed costs of providing control communication, developing metering evidence, permitting metering locations with the independent system operator, and maintaining EVSE units can be confined into a smaller number of locations while meeting the participation capacity requirements.

- Power quality management. In addition to frequency regulation and spinning reserves, EVSE and PEV can provide power quality management such as reactive power compensation. Many residential appliances, such as microwave ovens, washing machines, air conditioners, and refrigerators, require reactive power. Reactive power can also be used to compensate the voltage drops. The relative loss of reactive power is much greater than the relative loss of active power on the transmission lines when the power factor is not close to 1 [46]; thus, reactive power is best used when it is generated close to where it is needed. EVSE can use the PEVs' onboard power electronics to supply 
reactive power without appreciable battery current with the grid and thereby preserve the battery lifetime [47]. The reactive power provided by EVSE is also critical for local renewable energy integration in a microgrid where high PV power is available but provides only real power and the utilities want to reduce the reactive power support that would otherwise be provided by diesel generators [17].

- Peak demand reduction. Peak demand reduction at the building scale provides an interesting behind-the-meter service for V2G that could allow building owners to reduce their energy costs and thus provide direct incentives for deploying EVSE units. Unlike in the V1G scenario where peak demand reduction focuses on ensuring that PEVs do not add to demand charges at a building/campus, with V2G energy could be acquired at offpeak times and then used to reduce the demand at the peak and lower the demand charges. This could be considered as a type of energy arbitrage. But in this case, given that most utility charges are for capacity rather than energy, cost differences would provide little value. PEV charging time can be inferred from the NREL data example because uncontrolled charging suggests that peak charging in the early morning ends around 10 a.m. and with fast charging this would certainly be earlier in the morning. Therefore, peak demand events occurring until about 1-2 p.m. could be reduced while there is still time to recharge the PEV for its evening use. Connection time data and evening mobility energy requirements need to be studied further because charging after the 1-2 p.m. period may add to an already high demand period and create a new peak demand. 


\section{Summary}

This section summarizes the use cases discussed in previous sections and distinguishes them by the primary motivation from which the value is derived. End-user services, energy market services, and grid services are identified from the use cases. Societal services, as defined in the PNNL framework document [15], are not considered because they are less common than other services and no use case discussed earlier falls into this category. End-user services include building diagnostics and valuations, which support the operations and maintenance of end-use assets and enhance overall customer comfort and convenience. Energy market services support the efficient use of resources and assets by helping customers modify their energy consumption behavior via mechanisms such as TOU and real-time pricing. Grid services could include ancillary or regulatory services that buildings could provide using transactive mechanisms. Table 2 provides an overview of the service categories and individual use cases with a brief explanation. 
Table 2. Major Categories of Services Provided by Transactive Control of EVSE

\begin{tabular}{|c|c|c|}
\hline $\begin{array}{l}\text { Service } \\
\text { Category }\end{array}$ & Use Cases & Description \\
\hline \multirow{4}{*}{$\begin{array}{l}\text { End-User } \\
\text { Services }\end{array}$} & Critical load support & $\begin{array}{l}\text { Provide outage support to the critical loads of the home with the } \\
\text { energy in the PEV. PHEVs are more suitable for critical load } \\
\text { support than BEVs because a grid outage is unexpected. }\end{array}$ \\
\hline & $\begin{array}{l}\text { Charging capacity } \\
\text { deferral }\end{array}$ & $\begin{array}{l}\text { Reduce the EVSE installation cost by planning and managing } \\
\text { charge times. Require information from the driver. The cost } \\
\text { reduction is significant in large deployment scenarios. }\end{array}$ \\
\hline & $\begin{array}{l}\text { Trading positions in a } \\
\text { charging queue at a } \\
\text { multiplex EVSE }\end{array}$ & $\begin{array}{l}\text { The user monetizes the convenience of the quick departure time } \\
\text { and pays more than the energy costs. }\end{array}$ \\
\hline & $\begin{array}{l}\text { Monetizing delayed } \\
\text { EVSE charging to } \\
\text { prioritize fast charging }\end{array}$ & $\begin{array}{l}\text { Incentivize the delayed charging of Level } 2 \text { EVSE to reduce the } \\
\text { peak demand charge associated with the DC fast charger. Also } \\
\text { reduce the stress on distribution transformers. }\end{array}$ \\
\hline \multirow{4}{*}{$\begin{array}{l}\text { Energy } \\
\text { Market } \\
\text { Services }\end{array}$} & Dynamic pricing & $\begin{array}{l}\text { Benefit from lower charging rates by optimizing PEV charging for } \\
\text { dynamic rate, which may be either real-time or TOU. }\end{array}$ \\
\hline & $\begin{array}{l}\text { Local renewable } \\
\text { energy integration }\end{array}$ & $\begin{array}{l}\text { Benefit from local renewable energy generation and store the } \\
\text { energy locally using PEVs. This could avoid PEV recharging at } \\
\text { higher rate when local renewable energy is not available. }\end{array}$ \\
\hline & Energy arbitrage & $\begin{array}{l}\text { Reduce energy costs in a dynamic pricing environment by } \\
\text { recharging the PEV at a lower rate during nighttime and } \\
\text { discharging the PEV at higher rate. }\end{array}$ \\
\hline & $\begin{array}{l}\text { Peak demand } \\
\text { reduction }\end{array}$ & $\begin{array}{l}\text { Reduce peak demand charge by coordinating EV charging and } \\
\text { make it noncoincidental to building peak load. }\end{array}$ \\
\hline \multirow{4}{*}{$\begin{array}{l}\text { Grid } \\
\text { Services }\end{array}$} & $\begin{array}{l}\text { Distribution capacity } \\
\text { deferral }\end{array}$ & $\begin{array}{l}\text { Use a transactive control method to defer the cost of upgrading } \\
\text { transformers that may be strained by PEV charging through } \\
\text { coordinated charging behind the distribution transformer. }\end{array}$ \\
\hline & Demand response & $\begin{array}{l}\text { DR of EVSE may be more effective than curtailing other residential } \\
\text { loads because of its power rating. }\end{array}$ \\
\hline & Ancillary market & $\begin{array}{l}\text { EVSE owners can benefit financially by participating in ancillary } \\
\text { markets through an aggregator and providing grid services such } \\
\text { as frequency regulation and spinning reserves. }\end{array}$ \\
\hline & $\begin{array}{l}\text { Power quality } \\
\text { management }\end{array}$ & $\begin{array}{l}\text { EVSE can provide reactive power compensation for the utility to } \\
\text { increase the power transfer efficiency through transmission lines. }\end{array}$ \\
\hline
\end{tabular}




\subsection{Barriers to Transactive Control of Electric Vehicle Supply Equipment}

Transactive control of EVSE faces barriers in many areas of research, including distribution infrastructure, standardization, vehicle-building/grid integration, and large-scale demonstration. Figure 3 illustrates the barriers and R\&D opportunities; Table 3 provides a more detailed explanation of these barriers and opportunities. VOLTTRON, an agent-based platform developed by PNNL [18], is best suited for distributed control and sensing in the environment described in Figure 3. VOLTTRON enables the interactions between distributed energy resources, buildings, EVSE units, PEVs, service providers, and aggregators to achieve energy-efficient grid integration.

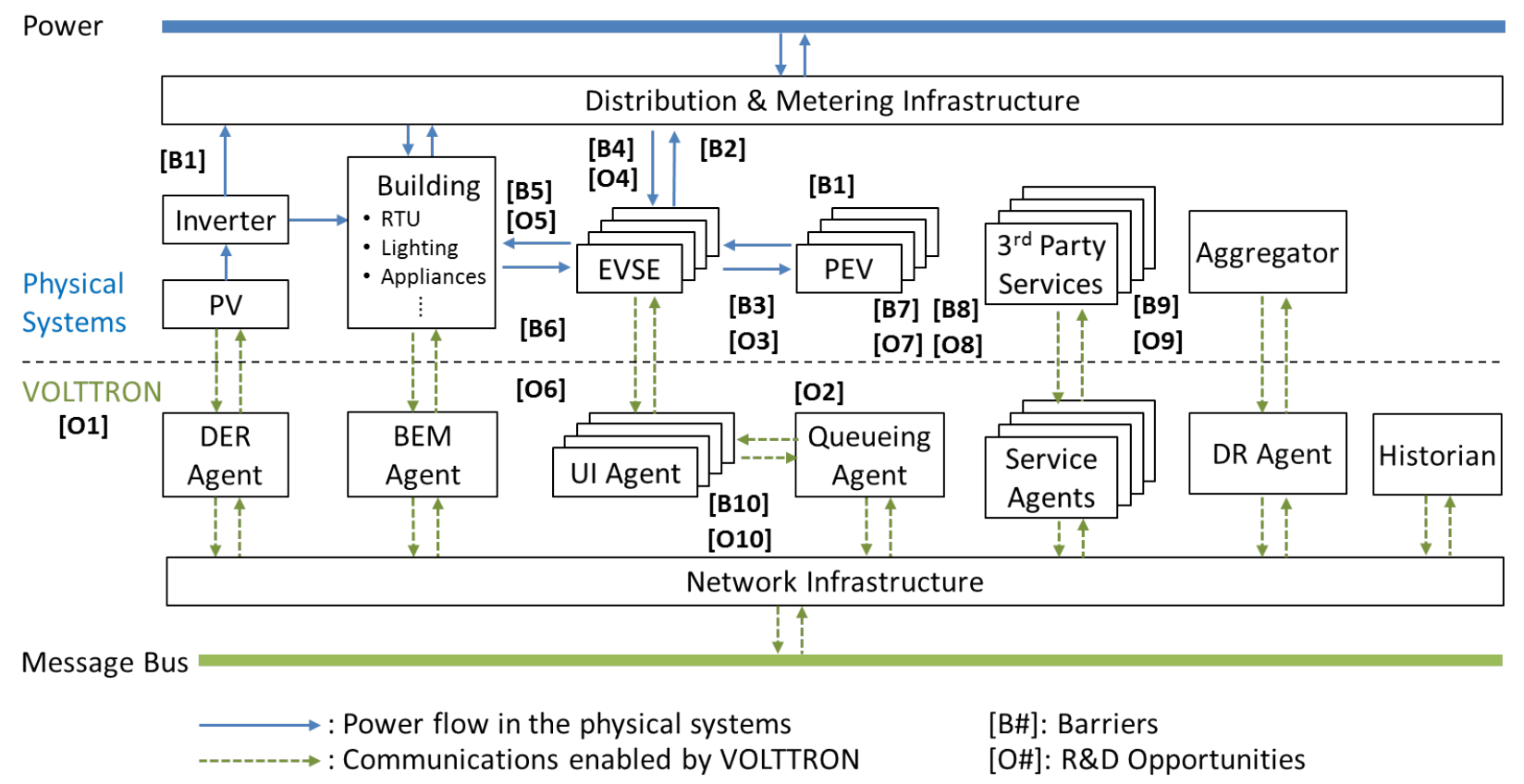

Figure 3. A block diagram illustrating challenges and opportunities for transactive control of EVSE 
Table 3. Key Barriers to Transactive Control of EVSE and Strategic R\&D Opportunities [17]

\begin{tabular}{|c|c|c|}
\hline Category & Barriers & R\&D Opportunities \\
\hline $\begin{array}{l}\text { Distribution } \\
\text { Infrastructure }\end{array}$ & $\begin{array}{l}\text { [B1] Conventional grid management uses } \\
\text { centralized control, which may no } \\
\text { longer be adequate to manage the } \\
\text { emergence of distributed generation } \\
\text { and EVSE. } \\
\text { [B2] The maximum EVSE hosting } \\
\text { capacity in a building is limited by the } \\
\text { power distribution infrastructure to } \\
\text { avoid overload caused by } \\
\text { coincidental peak loads from EVSE } \\
\text { and existing building end-uses. }\end{array}$ & $\begin{array}{l}\text { [O1] Explore distributed management } \\
\text { tools for grid/building-integration of } \\
\text { EVSE such as VOLTTRON, an } \\
\text { agent-based control platform. } \\
\text { [O2] Develop transactive control } \\
\text { algorithms to optimize the EVSE } \\
\text { charging schedule to avoid } \\
\text { coincidental peak loads and } \\
\text { maximum EVSE hosting capacity } \\
\text { with the current infrastructure. }\end{array}$ \\
\hline Standardization & $\begin{array}{l}\text { [B3] Multiple communication standards for } \\
\text { distributed energy resources } \\
\text { automation are available and major } \\
\text { vehicle-grid communication } \\
\text { standards do not map directly. }\end{array}$ & $\begin{array}{l}\text { [O3] Develop technologies and tools; e.g., } \\
\text { adapters and protocol translators, to } \\
\text { integrate new standardized devices } \\
\text { with legacy systems and proprietary } \\
\text { networks. }\end{array}$ \\
\hline $\begin{array}{l}\text { Vehicle- } \\
\text { Building/Grid } \\
\text { Integration }\end{array}$ & $\begin{array}{l}\text { [B4] The energy management and } \\
\text { optimization of PEV charging and } \\
\text { discharging to the grid and buildings } \\
\text { are still at early R\&D stage. } \\
\text { [B5] EVSE's capability to perform } \\
\text { grid/building services is largely limited } \\
\text { by the cost of hardware for enabling } \\
\text { bi-directional control. } \\
\text { [B6] The effectiveness of vehicle-building } \\
\text { integration may be limited because of } \\
\text { the uncertainties in PEV availability } \\
\text { and building equipment. }\end{array}$ & $\begin{array}{l}\text { [O4] Identify key variables and objective } \\
\text { functions for optimizing energy } \\
\text { management between EVSE units } \\
\text { and the grid/building. } \\
\text { [O5] Explore the service potential of } \\
\text { unidirectional and bidirectional } \\
\text { control with agent-based control } \\
\text { platform for EVSE. } \\
\text { [O6] Investigate the PEV availability } \\
\text { throughout the day and the feasibility } \\
\text { of using PEV to power building } \\
\text { equipment such as rooftop units, } \\
\text { lighting, and appliances. }\end{array}$ \\
\hline $\begin{array}{l}\text { Large-Scale } \\
\text { Demonstration }\end{array}$ & $\begin{array}{l}\text { [B7] Limited large-scale demonstration of } \\
\text { transactive network that includes } \\
\text { EVSE and distributed energy } \\
\text { resources, especially in the areas of } \\
\text { data collection, data management } \\
\text { and autonomous control. } \\
\text { [B8] Lack of understanding in the } \\
\text { dynamics and stability of large-scale } \\
\text { transactive markets. }\end{array}$ & $\begin{array}{l}\text { [O7] Develop hardware-in-the-loop (HIL) } \\
\text { testing systems to enable rapid } \\
\text { prototyping, evaluation, and } \\
\text { optimization of components and } \\
\text { control systems. } \\
\text { [O8] Leverage scaling studies, massively } \\
\text { parallel system simulation, and/or } \\
\text { HIL systems to study dynamics and } \\
\text { stability of large-scale transactive } \\
\text { markets. }\end{array}$ \\
\hline $\begin{array}{l}\text { User and } \\
\text { Service } \\
\text { Provider }\end{array}$ & $\begin{array}{l}\text { [B9] Third-party service provider (e.g., } \\
\text { payment verification, prognostics, } \\
\text { and health management) is not } \\
\text { available or does not have a well- } \\
\text { defined business model in the } \\
\text { transactive market. } \\
\text { [B10] Lack of user interface for PEV } \\
\text { owners to understand the value or } \\
\text { specify the preference in participating } \\
\text { in the transactive market. }\end{array}$ & $\begin{array}{l}\text { [O9] Engage with stakeholders to develop } \\
\text { VOLTTRON agents that provide } \\
\text { various types of services and explore } \\
\text { business models that benefit service } \\
\text { providers and end users in the } \\
\text { transactive market. } \\
\text { [O10] Develop user interface agents for } \\
\text { PEV owners to specify charging } \\
\text { preferences and obtain real-time } \\
\text { charging and market updates. }\end{array}$ \\
\hline
\end{tabular}




\subsection{Next Steps}

Transactive control delivers benefits to end users, the energy market, the electricity grid, and society as a whole. Transactive control of EVSE will benefit PEV owners, building owners, and utilities. It will also open up a new area for providing third-party services. To unlock the many benefits of transactive controls, DOE should engage stakeholders to initiate and support research work to overcome the barriers identified in Table 3.

To enhance DOE's efforts, NREL is proposing a project to address the potential needs of the stakeholders and demonstrate transactive control of EVSE in a realistic building environment. The proposed project will leverage the technical expertise of multiple national laboratories, such as NREL's strength in VGI and transactive network infrastructure in the Energy Systems Integration Facility (ESIF), PNNL's agent-based software VOLTTRON, and ANL's expertise in system integration and interoperability. The proposed project will demonstrate transactive control of EVSE in a commercial building environment such as ESIF with the application of peak demand management.

\subsubsection{Project Objectives}

The objective of the proposed project is to develop hardware and software platforms to demonstrate transactive control of EVSE at the building scale. When the demonstration is complete, the project will focus on improving interoperability of the developed platforms and performing large-scale HIL testing. The expected outcomes of the project include a low-cost and scalable solution for EVSE-grid integration and a deeper understanding of grid-connected EVSE behavior in a transactive energy market. The project will address the needs of EVSE

stakeholders as shown in Table 4, where VOLTTRON is suggested for potential actions to meet these needs. Successful demonstration of EVSE transactive control in ESIF will facilitate the wide adoption of VOLTTRON by industry stakeholders. 
Table 4. Potential Needs of EVSE Stakeholders and Corresponding Actions [17]

\begin{tabular}{|c|c|c|}
\hline Stakeholders & Needs & Proposed Actions \\
\hline PEV Owner & $\begin{array}{l}\text { - Information about the EVSE charging } \\
\text { option and its cost-benefit tradeoffs } \\
\text { - Real-time update of the charging status } \\
\text { such as charged energy and remaining } \\
\text { time }\end{array}$ & $\begin{array}{l}\text { Provide a (mobile) user interface for } \\
\text { users to specify charging preference. } \\
\text { - Create an agent to enable real-time } \\
\text { communication between the EVSE and } \\
\text { the user interface. }\end{array}$ \\
\hline Building Owner & $\begin{array}{l}\text { - Integration of building control with } \\
\text { EVSE control for energy cost reduction }\end{array}$ & $\begin{array}{l}\text { Develop an agent-based control } \\
\text { solution to coordinate individual EVSE } \\
\text { charging with building load for } \\
\text { renewables integration and demand } \\
\text { charge reduction. }\end{array}$ \\
\hline $\begin{array}{l}\text { EVSE } \\
\text { Manufacturer/ } \\
\text { Owner }\end{array}$ & $\begin{array}{l}\text { EVSE compatibility with multiple types } \\
\text { of utility/aggregator control needs to be } \\
\text { ensured }\end{array}$ & $\begin{array}{l}\text { - Collaborate with standards } \\
\text { organizations to develop } \\
\text { interoperability solutions. }\end{array}$ \\
\hline Utilities & $\begin{array}{l}\text { - Understanding the dynamics of a large- } \\
\text { scale transactive network with } \\
\text { hundreds of EVSEs and its impacts on } \\
\text { the power grid }\end{array}$ & $\begin{array}{l}\text { Perform HIL testing together with } \\
\text { supercomputer to study the dynamics } \\
\text { of large-scale EVSE transactive } \\
\text { control. }\end{array}$ \\
\hline $\begin{array}{l}\text { PEV } \\
\text { Manufacturers }\end{array}$ & $\begin{array}{l}\text { - Understanding the range of possible } \\
\text { use cases and the impact on battery } \\
\text { life }\end{array}$ & $\begin{array}{l}\text { - Collaborate with original equipment } \\
\text { manufacturers for HIL testing of the } \\
\text { PEVs on the V1G capabilities and } \\
\text { future V2G capabilities. }\end{array}$ \\
\hline
\end{tabular}

\subsubsection{Tasks}

Table 5 shows five proposed tasks to address the issues identified in Table 3 and meet the potential needs of EVSE stakeholders. Tasks 1-3 focus on hardware and software development for transactive control of EVSE and demonstration using the transactive network infrastructure. Tasks 4 and 5 extend the project and focus on improving interoperability and large-scale testing. 
Table 5. Proposed Tasks for Overcoming Barriers to Transactive Control of EVSE

\begin{tabular}{|c|c|}
\hline Task Name & Description \\
\hline $\begin{array}{l}\text { TASK 1: Prototype a modular } \\
\text { embedded platform for } \\
\text { transactive control of EVSE } \\
\text { using VOLTTRON }\end{array}$ & $\begin{array}{l}\text { Develop an embedded hardware platform to interface with EVSE and } \\
\text { implement transactive control. Implement VOLTTRON on a low-cost } \\
\text { single-board computer and develop necessary peripherals to } \\
\text { interface with EVSE. Make the embedded platform modular such that } \\
\text { it can also be used to control other equipment connected to the } \\
\text { transactive network infrastructure. }\end{array}$ \\
\hline $\begin{array}{l}\text { TASK 2: Develop an EVSE } \\
\text { agent for optimizing charging } \\
\text { based on user preference and } \\
\text { peak demand constraints }\end{array}$ & $\begin{array}{l}\text { Develop an EVSE agent that offers a user interface for EVSE users } \\
\text { to provide information, such as departure time, amount of energy to } \\
\text { be charged, and willingness to trade charging positions. This } \\
\text { information will enable transactive control among a group of EVSE } \\
\text { units in the transactive network. The EVSE agent will communicate } \\
\text { with the EVSE unit for data collection and control the EVSE charging } \\
\text { rate. }\end{array}$ \\
\hline $\begin{array}{l}\text { TASK 3: Demonstrate a } \\
\text { transactive control of EVSE } \\
\text { for peak demand } \\
\text { management }\end{array}$ & $\begin{array}{l}\text { Integrate the hardware platform and software interface developed } \\
\text { under Tasks } 1 \text { and } 2 \text { and demonstrate EVSE transactive control } \\
\text { using the transactive network for peak demand management. The } \\
\text { EVSE agents will coordinate with building energy management } \\
\text { agents, PV inverter agents, weather agents, and others in the } \\
\text { transactive network to reduce the demand charge and still meet the } \\
\text { user-specified charging requirements. During peak load hours, the } \\
\text { EVSE units that are willing to trade charging positions will be curtailed } \\
\text { and be provided with incentives. The EVSE agents will also record } \\
\text { the charging profile for studying the potential impact on the PEV } \\
\text { battery life. }\end{array}$ \\
\hline $\begin{array}{l}\text { TASK 4: Improve the } \\
\text { interoperability of the } \\
\text { embedded platform by using } \\
\text { an extension board }\end{array}$ & $\begin{array}{l}\text { Improve the interoperability of the embedded platform developed } \\
\text { under Task } 1 \text { and fabricate an extension board that can be stacked } \\
\text { on the embedded platform. The extension board will serve as an } \\
\text { adapter and protocol translator and provide interoperability solutions } \\
\text { for communicating with legacy systems and proprietary networks. }\end{array}$ \\
\hline $\begin{array}{l}\text { TASK 5: Conduct large-scale } \\
\text { testing in the transactive } \\
\text { network using HIL test-bed } \\
\text { and supercomputer }\end{array}$ & $\begin{array}{l}\text { Implement a large-scale testing using transactive network } \\
\text { infrastructure such as the one in ESIF. An auction type of transactive } \\
\text { energy market will be used to reduce computation load. Leverage a } \\
\text { HIL test bed and petaflop-scale supercomputer to study the dynamics } \\
\text { and effectiveness of EVSE transactive control in a large-scale } \\
\text { transactive network with hundreds of EVSE units. Perform strategic } \\
\text { analysis to evaluate market potential and value chain. }\end{array}$ \\
\hline
\end{tabular}




\section{References}

[1] Silver Spring Networks, "How the Smart Grid Enables Utilities to Integrate Electric Vehicles".

[2] S. Shepard and L. Jerram, "Electric Vehicle Supply Equipment Tracker 3Q13," Navigant Research, 2013.

[3] L. T. Berger and K. Iniewski, "Smart Grid Applications, Communications, and Security," Wiley, 2012.

[4] SAE International, "SAE Electric Vehicle and Plug in Hybrid Electric Vehicle Conductive Charge Coupler," 2012.

[5] TEPCO, "General Outline of "CHAdeMO Association"," 2010.

[6] G. Kissel, "SAE J1772 Update For IEEE Standard 1809 Guide for Electric-Sourced Transportation Infrastructure Meeting," SAE International, 2010.

[7] SAE International, "New SAE International Quick-Charge EV Connector Standard Gaining Momentum," 2011.

[8] Tesla Supercharger, 2015. [Online]. Available: http://www.teslamotors.com/supercharger.

[9] K. Gogineni, "ChargePoint America," 2013. [Online]. Available:

http://energy.gov/sites/prod/files/2014/03/f13/arravt073_vss_gogineni_2013_o.pdf.

[10] ECOtality, "The EV Project," [Online]. Available: http://www.theevproject.com/overview.php.

[11] J. Smart, "Latest insights from the EV Project and ChargePoint America PEV infrastructure demos," GITT meeting at Idaho National Laboratory, 2014.

[12] L. Jerram and J. Gartner, "Electric Vehicle Charging Equipment: Level 1, Level 2, DC Fast Charging, and Wireless EVSE for Residential and Commercial Passenger Car Charging"," Navigant Research, 2013.

[13] L. Jerram, "Bosch Goes Basic With EV Charger," Navigant Research, 2014.

[14] U.S. Department of Energy, "Buildings Energy Data Book," [Online]. Available: http://buildingsdatabook.eren.doe.gov/.

[15] S. Somasundaram, R. Pratt, B. Akyol, N. Fernandez, N. Foster, S. Katipamula, E. Mayhorn, A. Somani, A. Somani, A. Steckley and Z. Taylor, "Transaction-Based Building Control Framework, Volume 1: Reference Guide," Pacific Northwest National Laboratory, Richland, WA, 2014. 
[16] "GridWise Transactive Energy Framework," Pacific Northwest National Laboratory, Richland, WA, 2015.

[17] M. Tony, A. Meintz, K. Hardy, B. Chen, T. Bohn, J. Smart, D. Scoffield, R. Hovsapian, S. Saxena, J. MacDonald, S. Kiliccote, K. Kahl and R. Pratt, "Multi-Lab EV Smart Grid Integration Requirements Study: Providing Guidance on Technology Development and Demonstration," NREL TP-540063963, 2015.

[18] J. Haack, B. Akyol, B. Carpenter, R. Pratt and T. Carroll, "VOLTTRON: An Agent Platform for Integrating Electric Vehicles and Smart Grid," in 2013 International Conference on Connected Vehicles and Expo (ICCVE), Las Vegas, 2013.

[19] Fraunhofer IIS, "OGEMA 2.0," [Online]. Available:

http://www.iis.fraunhofer.de/en/ff/ener/proj/ogema-2-0.html..

[20] FlexiblePower Application Infrastructure (FPAI), [Online]. Available: https://github.com/flexiblepower/fpai-core/wiki/FPAI.

[21] AeroVironment, "AeroVironment Smart Charging Station," [Online]. Available: http://evsolutions.avinc.com/products/workplace/smart_charging_station3.

[22] BTCPower, [Online]. Available: http://www.btcpower.com/.

[23] ChargePoint, [Online]. Available: http://www.chargepoint.com/.

[24] ChargePoint, "BMW, Volkswagen and ChargePoint Announce Initiative to Create Electric Vehicle Express Charging Corridors on the East and West Coasts," 2012. [Online]. Available: http://www.chargepoint.com/press-releases/2015/0122.

[25] ClipperCreek, [Online]. Available: http://www.clippercreek.com/.

[26] SmartGridToday, "Delta, DOE, DTE show off smart grid connected EV chargers," [Online]. Available: http://www.smartgridtoday.com/public/Delta-DOE-DTE-show-off-smart-gridconnectedEV-chargers.cfm.

[27] GE Energy, "GE WattStation Pedestal EVSE Charger - MODBUS Register Mapping Guide," [Online]. Available: http://apps.geindustrial.com/publibrary/checkout/DEH41581A?TNR=Installation\%20and\%20Instruction\%7CDEH-41581A\%7Cgeneric.

[28] University of Hawaii Maui College, "EVs in Paradise: Planning for the Development of Electric Vehicle Infrastructure in Maui County," 2012.

[29] Siemens, "VersiCharge Electric Vehicle Charging Station - Preliminary Data Sheet," [Online]. Available: http://w3.siemens.com/powerdistribution/global/EN/lv/greenapplications/electromobility/Documents/PDDS-VERSI-0811_V2.pdf. 
[30] Greenlots, [Online]. Available: http://greenlots.com/.

[31] UDaily, "Officials celebrate as electric vehicle-to-grid technology sells power to PJM power grid," 2013. [Online]. Available: http://www.udel.edu/udaily/2013/apr/electric-vehicles-042613.html.

[32] BMW, "Introducing the BMW i Chargeforward Program," [Online]. Available: http://www.bmwichargeforward.com/.

[33] EPRI Press Release, "EPRI, Utilities, Auto Manufacturers to Create an Open Grid Integration Platform for Plug-in Electric Vehicles," 297 2014. [Online]. Available: http://www.epri.com/PressReleases/Pages/EPRI,-Utilities,-Auto-Manufacturers-to-Create-an-Open-Grid-IntegrationPlatform.aspx.

[34] Xcel Energy, "Electric Vehicle Charging Station Pilot," [Online]. Available: https://www.xcelenergy.com/staticfiles/xe/Marketing/Files/CO-Res-EVCS-Pilot-Sign-Up-Form.pdf.

[35] SAE International, "Interconnection requirements for onboard, utility-interactive, inverter systems," [Online]. Available: http://standards.sae.org/wip/j3072/.

[36] S. Kazbour, "Spiders-II Vehicle to Grid Demonstration at Fort Carson, CO - Final Report," U.S. Army Tank Automotive Research, Development Engineering Center (TARDEC), Warren, MI, 2014.

[37] J. D. Herper, "Development and Implementation of SAE DC Charging Digital Communication for Plug-in Electric Vehicle DC Charging," SAE International, 2013-01-1188, 2013.

[38] ComEd Real-time Pricing, [Online]. Available: https://rtp.comed.com/live-prices/.

[39] EV Rates, [Online]. Available: http://www.sdge.com/clean-energy/ev-rates.

[40] California Public Utilities Commission, [Online]. Available: http://docs.cpuc.ca.gov/PUBLISHED/FINAL_DECISION/106042-02.htm.

[41] PG\&E, "Demand Response Energy Reduction Strategies," [Online]. Available: http://www.pge.com/en/mybusiness/save/energymanagement/energyreductionstrategies/index.page.

[42] U.S DOE and U.S. EPA, "the official U.S. government source for fuel economy information," [Online]. Available: www.fueleconomy.gov.

[43] PJM, "Ancillary Services," [Online]. Available: http://www.pjm.com/markets-andoperations/ancillary-services.aspx.

[44] W. Kempton and J. Tomic, "Vehicle-to-Grid Power Fundamentals: Calculating capacity and net revenue," 2008. [Online]. Available: http://www.udel.edu/V2G/resources/test-v2g-in-pjm-jan09.pdf. 
[45] Forward Market Operations, "PJM Manual 11: Energy \& Ancillary Services Market Operations," 2014.

[46] Federal Energy Regulatory Commission, "Principles for efficient and reliable reactive power supply and consumption," 2015.

[47] M. C. Kisacikoglu, B. Ozpineci and L. M. Tolbert, "Examination of a PHEV bidirectional charger for $\mathrm{V} 2 \mathrm{G}$ reactive power compensation," in Proc. IEEE APEC Expo, Palm Springs, CA, USA, 2010.

[48] DOE Office of EERE, "EV Everywhere Workplace Charging Challenge," [Online]. Available: http://energy.gov/eere/vehicles/ev-everywhere-workplace-charging-challenge.

[49] Blink DC Fast Charger, [Online]. Available: http://www.blinknetwork.com/chargers-commercial-dcfast.html.

[50] InsideEVs, "BMW Launches New Low Cost DC Fast Chargers From \$6,458," [Online]. Available: http://insideevs.com/bmw-launches-new-low-cost-dc-fast-chargers-6458/. 